NBER WORKING PAPER SERIES

\title{
SUBJECTIVE PERFORMANCE MEASURES IN OPTIMAL INCENTIVE CONTRACTS
}

\author{
George Baker \\ Robert Gibbons \\ Kevin J. Murphy
}

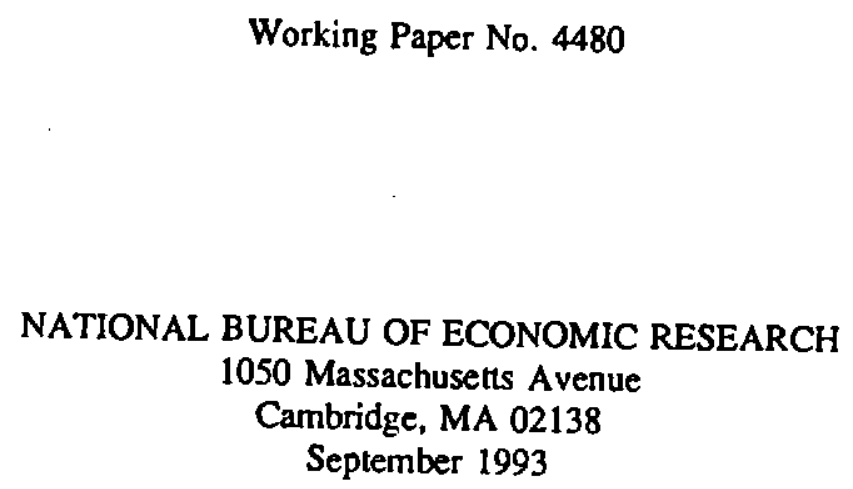

We are very grateful for helpful discussions with Gary Becker, David Besanko, Bengt Holmström, Kevin Lang, Kevin M. Murphy, Canice Prendergast, James Rebitzer, Richard Thaler, Karen Van Nuys, and Michael Waldman, as well as for useful comments from participants at numerous seminars. We also appreciate financial support from the Division of Research at Harvard Business School (Baker and Murphy); and the NSF (SES-9010759) and an A.P. Sloan Research Fellowship (Gibbons). This paper is part of NBER's research program in Labor Studies. Any opinions expressed are those of the authors and not those of the National Bureau of Economic Research. 
NBER Working Paper \#4480

September 1993

\title{
SUBJECTIVE PERFORMANCE MEASURES \\ IN OPTIMAL INCENTIVE CONTRACTS
}

\begin{abstract}
Objective measures of performance are seldom perfect. In response. incentive contracts often include important subjective components that mitigate incentive distortions caused by imperfect objective measures. This paper explores the combined use of subjective and objective performance measures in (respectively) implicit and explicit incentive contracts.

Naturally, objective and subjective measures often are substitutes, sometimes strikingly so: we show that if objective measures are sufficiently close to perfect then no implicit contracts are feasible (because the firm's fallback position after reneging on an implicit contact is too attractive). We also show, however, that objective and subjective measures can reinforce each other: if objective measures become more accurate then in some circumstances the optimal contract puts more weight on subjective measures (because the improved objective measures increase the value of the ongoing relationship, and so reduce the firm's incentive to renege). We also analyze the use of subjective weights on objective performance measures, and provide casestudy evidence consistent with our analyses.
\end{abstract}

George Baker

Harvard Business School

Soldiers Field Road

Boston, MA 02163

Robert S. Gibbons

Johnson Graduate School of Management

Comell University

507 Mallott Hall

Ithaca, NY 14853

and NBER
Kevin J. Murphy

Harvard Business School

Soldiers Field Road

Boston, MA 02163 


\title{
Subjective Performance Measures in Optimal Incentive Contracts
}

\author{
by \\ George Baker, Robert Gibbons, and Kevin J. Murphy
}

\section{Introduction}

\section{A. Motivation}

Business history is littered with firms that got what they paid for. At the H.J. Heinz Company, for example, division managers received bonuses only if earnings increased from the prior year. The managers delivered consistent earnings growth by manipulating the timing of shipments to customers and by prepaying for services not yet received. ${ }^{1}$ At Dun \& Bradstreet, salespeople eamed no commission unless the customer bought a larger subscription to the firm's credit-report services than in the previous year. In 1989, the company faced millions of dollars in lawsuits following charges that its salespeople deceived customers into buying larger subscriptions by fraudulently overstating their historical usage. ${ }^{2}$ In 1992, Sears abolished the commission plan in its auto-repair shops, which paid mechanics based on the profits from repairs authorized by customers. Mechanics misled customers into authorizing untecessary repairs, leading Califomia officials to prepare to close Sears' autorepair business statewide. ${ }^{3}$

In each of these cases, employees took actions to increase their compensation, but these actions were seemingly at the expense of long-run firm value. At Heinz, for example, prepaying for future services greatly reduced the firm's future flexibility, but the compensation system failed to address this issue. Similarly, at Dun \& Bradstreet and Sears, although short-run profits increased with the increases in subscription sizes and auto repairs, the long-run harm done to the firms' reputations was significant (and plausibly much larger than the short-run benefit), but the compensation system again ignored the issue. Thus, in each of these cases, the cause of any dysfunctional behavior was not pay-for-performance per se, but rather pay-for-performance based on an inappropriate performance measure. 1 Post, Richard J. and Kenneth E. Goodpaster, "HJ. Heinz Company: The Administration of Policy,"
HBS Case $\$ 382-034$.

2 Roberts, Johnnie L., "Credit Squeeze: Dun \& Bradstreet Faces Flap Over How It Sells Reports on Businesses," Wall Street Journal, March 2, 1989.

3 Patterson, Gregory, "Distressed Shoppers, Disaffected Workers Prompt Stores to Alter Sales Commission," Wall Street Journal, June 1, 1992. 
Many firms mitigate the effects of distortionary objective performance measures by augmenting objective measures with subjective assessments of performance. Investment bankers involved in corporate finance, for example, could be measured by several objective performance measures, such as fees generated. Nonetheless, most investment banks devote significant resources to subjectively assessing other factors such as the "quality of the deals, the bankers' contributions to customer satisfaction, training of younger associates, and marketing" (Eccles and Crane, 1988, p. 166). Even in the sales and trading function of an investment bank, where more accurate objective aspects of an individual's contribution to firm value are easily measured on a daily basis, banks again deliver a significant amount of a trader's compensation through a subjectively determined bonus (Eccles and Crane, p. 170).

Lincoln Electric, the dominant manufacturer of arc welding equipment, provides another example of the combined use of objective performance measurement and subjective performance assessment. Since its founding in 1895, the firm has continuously reduced costs and increased quality; it drove General Electric from the arc-welder market and reduced Westinghouse to a bit player. Lincoln has been called "the holy shrine of incentive pay" (Perry, 1988, p. 51), in part because the firm creates strong incentives through piece-rate pay based on objective performance measures. A second element of Lincoln's compensation package also creates strong incentives, however: in a typical year, half a worker's pay comes from a bonus based on management's assessment of the worker's cooperation, innovation, dependability, and other subjective aspects of performance.

\section{B. Analytical Framework}

An ideal performance measure would reflect an employee's contribution to firm value, including both static externalities across business units and dynamic effects of current actions on long-run value. Basing pay on an employee's contribution to firm value would have prevented the seemingly dysfunctional behaviors at Heinz, Dun \& Bradstreet, and Sears. Unfortunately, for most employees, contribution to firm value is not objectively measurable: market-adjusted stock-price performance may be a useful measure of a CEO's contribution but typically is an extremely noisy measure of the contributions of lower-level employees.

When an employee's contribution to firm value is not objectively measurable, it often can be subjectively assessed by managers or supervisors who are well placed to observe the subtleties of the employee's behavior and opportunities. Even if such subjective assessments of an employee's contribution to firm value are imperfect, they may complement or improve on the available objective measures. Thus, an implicit contract based on subjective 
performance assessments may augment or replace an explicit contract based on objective performance measurements.

While an explicit contract can be enforced by a court, an implicit contract cannot, and so is vulnerable to reneging by the firm. Numerous observers of organizational pay practices have noted that trust between workers and supervisors is essential if subjective performance assessment systems are to be successful (Lawler, 1971; Hamner, 1975). We formalize (part of) the notion of trust in performance evaluation by requiring that implicit contracts based on subjective performance assessments be enforced not by the courts but by the firm's concem for its reputation in the labor market (Holmström, 1981; Bull, 1987). Thus, an implicit contract could also be called a self-enforcing contract.

In this paper, we assume that the only objective measure of performance is imperfect, so when used alone it causes the worker to take suboptimal actions. We develop two models of subjective performance assessment. In our first analysis, the firm and the worker observe a subjective assessment of performance in addition to the imperfect objective measure. Naturally, such objective and subjective measures often are substitutes, sometimes strikingly so: we show that if the objective measure is sufficiently close to perfect then no implicit contract is feasible (because the firm's fallback position after reneging on an implicit contract is too attractive). We also show, however, that objective and subjective measures can reinforce each other: if the objective measure becomes more accurate then in some circumstances the optimal contract puts more weight on the subjective measure (because the improved objective measure increases the value of the ongoing relationship, and so reduces the firm's incentive to renege).

This first analysis yields three comparative-static predictions. First, if the value of the ongoing relationship between the firm and the worker falls, the implicit contracts the firm can sustain will be less effective, so the incentives provided by implicit contracts will decrease, and those provided by explicit contracts will increase. Second, if objective performance measures become more accurate (such as after a division is spun off from a conglomerate), the incentives provided by implicit contracts decrease if the fallback contract is sufficiently attractive but increase otherwise. Third, if it becomes more difficult for the firm to produce accurate subjective performance assessments (such as after expansion or diversification of the firm's operations), the incentives provided by implicit and explicit contracts will decrease and increase, respectively. We provide case-study evidence consistent with these predictions.

In our second analysis we assume that the firm can subjectively evaluate the incentive distortions caused by the imperfect objective performance measure. In this case, the optimal incentive contract attaches a subjective weight (or a subjective piece-rate) to the objective performance measure, to "back out" or moderate the distortions that would be created by the 
optimal explicit contract. We show that the contract between the worker and the firm is left deliberately vague: although there is an explicit understanding of how performance is measured, there is only an implicit understanding regarding how that objective performance measure is rewarded. The optimal incentive contract combines both objective and subjective weights on the objective performance measure, because increasing the objective weight reduces the employer's incentive to renege on large payoffs prescribed by the subjective weight. We provide case-study evidence of the use of such subjective weights on objective performance measures.

\section{C. Outline}

Our analyses integrate and extend two benchmark models from the literature-one concerning implicit contracts and another concerning explicit contracts. In Section 2 we develop our model and analyze these two benchmarks: in Section $2 \mathrm{~A}$ we describe the economic environment for our model (i.e., the information structure, preferences, production and contracting possibilities, and chronology of events), and in Sections $2 \mathrm{~B}$ and $2 \mathrm{C}$ we present the two benchmark models.

The first benchmark is Baker's (1992) model of an explicit contract. Unlike agency models such as Holmström's (1979), Baker assumes that the worker's contribution to firm value is too complex and subtle to be objectively measured, and so cannot be the basis of an enforceable contract. Any explicit contract therefore must be based on an imperfect objective measure of the worker's contribution-such as the quantity but not the quality of a worker's output-but using such a measure causes workers to take suboptimal actions. ${ }^{4}$ Naturally, the slope of the optimal explicit contract falls as the distortions in the objective performance measure increase.

The second benchmark is a repeated-game model of an implicit contract, much like Bull's (1987). The firm would like the worker to be cooperative, innovative, and dependable, and offers to pay the worker a bonus based on these subjective aspects of performance. If the firm has no concern for its reputation, its incentive is to claim that the worker performed poorly and so deserves no bonus. If the firm values its reputation, however, it must weigh the temptation to stiff the worker today against the present value of the benefits from future cooperation, innovation, and dependability, and the costs of future bonuses. The optimal subjective bonus plan is self-enforcing: the bonus must be sufficiently small that the firm has no incentive to renege. If the firm's discount rate is sufficiently low then the present value of being trustworthy is large enough that an implicit contract can

\footnotetext{
4 Hoimstrom and Milgrom's (1991) model is similar in spirit to Baker's. An analogous analysis of
} implicit and explicit contracts could be built on their model rather than Baker's. 
achieve the first-best outcome; otherwise, the best feasible implicit contract requires a smaller bonus and so produces second-best incentives.

In Section 3 we combine the benchmark models from Sections $2 \mathrm{~B}$ and $2 \mathrm{C}$ to analyze the optimal interplay between subjective performance assessments and objective performance measures in implicit and explicit contracts. In each period, part of compensation is an explicit contract based on the objective measurement of an imperfect proxy for the worker's contribution, and part is a bonus based on a subjective assessment of the worker's contribution to firm value. In the latter part of this section, we relax our assumption that the subjective assessment is noncontractible but otherwise perfect; our qualitative results extend to such imperfect subjective assessments.

In Section 4 we explore the use of subjective weights on imperfect objective performance measures. Here we assume that, after the worker's performance has been observed, the employer or supervisor can subjectively assess the distortions caused by the objective performance measure. (In practice, such ex post judgments seem likely to be incomplete or imprecise, but in this exploratory analysis we assume they are perfect.) Although the firm would like to use its subjective assessment to eliminate all the distortions in the objective performance measure, it faces the same reputation problem as in Section 3-the firm cannot credibly commit to very high subjectively determined payoffs. We explore the tradeoff between objective and subjective piece rates on objective performance measures: increasing the objective piece rate reduces the employer's incentive to renege on high total payoffs (by reducing the subjective portion of the high payoff); but typically also provides excessive incentives in some states of the world.

In Section 5 we present case-study evidence consistent with our analyses. We offer the cases as independently gathered qualitative observations of organizational practices consistent with not only the predictions but also the underlying causal mechanisms of our models. In presenting each case, we use our models to organize the welter of case facts into a logically consistent and intuitive analysis.

Finally, in Section 6 we discuss three potential extensions of our analysis: supervisor bias in subjective performance assessment, the use of multiple subjective evaluators, and the interplay between explicit pay-for-performance contracts and implicit promotion contracts (rather than the implicit pay-for-performance contracts we study here). 


\section{Benchmark Models}

\section{A. The Economic Environment}

We consider a repeated game between a single firm and a single worker. ${ }^{5}$ In each period, the worker chooses an unobservable action, a, that stochastically determines the worker's contribution to firm value, $y$. To keep things as simple as possible, we assume that $y$ equals either zero or one. It is then natural to define the worker's action to be the probability that $y=1: \operatorname{Prob}\{y=1 \mid a\}=a$, where $a \in[0,1]$. As discussed in the Introduction, we assume that the worker's contribution to firm value is too complex and subtle to be verified by a third party, and so cannot be the basis of an enforceable contract. That is, y cannot be objectively measured. On the other hand, we assume that $y$ can be subjectively assessed (as explained below).

The worker's action also affects a second performance measure, p. Like y, p equals either zero or one (although any other pair of values would do as well, because $p$ is not directly relevant to the parties' payoffs, as will become clear). Unlike $y$, however, $p$ can be objectively measured, and so can be the basis of an explicit contract.

The objective performance measure $p$ is an imperfect proxy for the worker's contribution to firm value, in the following sense. Before choosing an action, the worker receives private information (denoted by $\mu>0$ ) about the difference between the effect of the worker's action on $y$ and its effect on $p$. The probability that $p=1$ is $\mu \cdot a$ (where we assume that the support of $\mu$ and the shape of the disutility function introduced below are such that $\mu \cdot a<1)$. For simplicity, we assume that given $\mu$ and a, the events that $y=1$ and that $p=1$ are independent. We interpret $\mu$ as follows: there are days (i.e. values of $\mu$ ) when high actions increase both $y$ and $p$, days when high actions increase $y$ but not $p$, and days when small actions increase $p$ but not $y$; these "days" correspond to $\mu$ around one, $\mu$ near zero, and $\mu$ much larger than one, respectively. We assume that $E(\mu)=1$ so that, on average, the performance measure $p$ is an unbiased measure of contribution $y$, but this normalization does not affect our qualitative results.

Compensation contracts consist of a base salary, s, an implicit-contract bonus b paid when the subjective assessment is $y=1$, and an explicit-contract bonus $\beta$ paid when the objective measure is $p=1$. The worker's total compensation is therefore either $s, s+b, s+$ $\beta$, or $s+b+\beta$. The timing of events within each period is as follows. First, the firm offers

5 The single worker we consider could just as well be an infinite sequence of workers, each of whom lives for one period, provided that each period's worker learns the history of play before the period begins. 
the worker a compensation package $(s, b, \beta)$. Second, the worker either accepts the compensation package or rejects it in favor of an altemative employment opportunity with payoff $w_{a}$. Third, if the worker accepts then the worker observes $\mu$ and then chooses an action $a \geq 0$ at cost $c(a)$. The firm does not observe $\mu$ or the worker's action. Fourth, the firm and the worker observe the realization of the worker's contribution, $y$, and the firm and the worker (and, if necessary, a court) observe the realization of the objective performance measure, $p$. Finally, if $\mathrm{p}=1$ then the firm pays the bonus $\beta$ dictated by the explicit contract, and if $y=1$ then the firm chooses whether to pay the worker the bonus b specified in the implicit contract.

The firm's payoff when the worker's contribution is $y$ and total compensation is $I$ is $y$ - I. The firm's discount rate is $r$, in our analysis, the worker's discount rate is immaterial, because it is the firm's reputation that is at stake. The worker's payoff from choosing an action with cost $c(a)$ and receiving total compensation I is $I-c(a)$. In order to compute various closed-form solutions, we assume that $c(a)=\gamma a^{2}$. The first-best action, which equates the expected marginal product of effort with its marginal cost, therefore satisfies $1=$ $c^{\prime}\left(a^{*}\right)$, or $a^{*}=1 / 2 \gamma$.

Given an implicit contract $b$ and an explicit contract $\beta$, if the worker believes the firm will honor the implicit contract then the worker's problem after observing a realization of $\mu$ is

$$
\max _{a} s+a \cdot b+\mu \cdot a \cdot \beta-\gamma a^{2}
$$

so the worker's optimal action is

$$
a^{*}(\mu, b, \beta)=\frac{b+\mu \beta}{2 \gamma} \text {. }
$$

Since the first-best action is $a^{*}=1 / 2 \gamma$, effort will be less than the first-best level whenever $b+\mu \beta<1$.

The worker will choose to work for the firm if his expected payoff (before observing H) exceeds the alternative wage:

$$
E_{\mu}\left(s+a^{*}(\mu, b, \beta) \cdot b+\mu \cdot a^{*}(\mu, b, \beta) \cdot \beta-\gamma a^{*}(\mu, b, \beta)^{2}\right) \geq w_{a}
$$

The firm's expected profit per period, given an implicit contract $b$ and an explicit contract $\beta$ but before the worker observes the realization of $\mu$ is

$$
E_{\mu}\left(a^{*}(\mu, b, \beta)-\left[s+a^{*}(\mu, b, \beta) \cdot b+\mu \cdot a^{*}(\mu, b, \beta) \cdot \beta\right]\right] .
$$


The firm's optimal base salary $s$ will be the lowest salary satisfying (2.3). Substituting this salary into (2.4) yields the firm's expected profit per period as a function of the implicit bonus $b$ and the explicit piece-rate $\beta$, which we denote by $V(b, \beta)$ :

$$
V(b, \beta) \equiv E_{\mu}\left\{a^{*}(\mu, b, \beta)-a^{*}(\mu, b, \beta)^{2}-w_{a}\right\}
$$

\section{B. An Explicit Contract Based on an Objective Performance Measure}

In this sub-section we ignore implicit contracts based on the subjective performance measure $y$, focusing instead on explicit contracts based on the imperfect proxy for the worker's contribution to firm value-the objective performance measure, p. Given an explicit contract $\beta$, the worker's optimal action after observing the realization of $\mu$ follows from (2.2):

$$
a^{*}(\mu, \beta)=\frac{\mu \beta}{2 \gamma}
$$

The optimal contract again sets the salary $s$ at the minimum value that satisfies (2.3), and now sets $\beta$ to maximize the expected profit per period,

$$
\max _{\beta} E_{\mu}\left\{a^{*}(\mu, \beta)-\gamma^{*}(\mu, \beta)^{2}-w_{a}\right\}
$$

Solving the first-order condition for (2.7), and recalling that $E\left\{\mu \mid=1\right.$ and $E\left\{\mu^{2}\right\}=1+\operatorname{var}(\mu)$, implies that the optimal explicit-contract bonus is

$$
\beta^{*}=\frac{E_{\mu}(\mu)}{E_{\mu}\left(\mu^{2}\right)}=\frac{1}{1+\operatorname{var}(\mu)}
$$

We denote the resulting expected profit for the firm by $V\left(\beta^{*}\right)$ :

$$
V\left(\beta^{*}\right)=\frac{1}{4 \gamma[1+\operatorname{var}(\mu)]}-w_{a} .
$$

The intuition behind this analysis is as follows. When the variance of $\mu$ is large, the marginal product of the worker's action on $p(n a m e l y, \mu$ ) is a noisy reflection of the marginal product of the worker's action on $y$ (namely, one). Consider the effect of setting $\beta=1$ when the variance of $\mu$ is large: the worker will choose the first-best action when $\mu=1$, but otherwise $a^{*}(\mu, 1)$ will vary wildly with $\mu$. Given the convex cost function $c(a)=\gamma^{2}$, the worker's expected cost $E_{\mu}\{c[a *(\mu, 1)]\}$ will be high, and the firm will have to compensate the worker for this expected cost in the salary defined by (2.3). The firm's optimal response is to offer a low value of $\beta$, thereby settling for weak incentives rather than strong but 
frequently dysfunctional incentives. (Compare this prescription to the seemingly dysfunctional incentive schemes at Heinz, Dun \& Bradstreet, and Sears.) Since $\beta^{*}$ and V( $\left.\beta^{*}\right)$ fall as the variance of $\mu$ rises, we will say that the objective performance measure $p$ is more distortionary when $\operatorname{var}(\mu)$ is higher.

\section{C. An Implicit Contract Based on a Subjective Performance Assessment}

To complement the previous sub-section, we now ignore explicit contracts based on the imperfect objective performance measure, focusing instead on the incentives that implicit contracts can provide. Our analysis is much like Bull's, and also is similar in some respects to those of Becker and Stigler (1974) and Shapiro and Stiglitz (1984). In the latter models, however, incentives follow from the threat of terminating the relationship following poor performance, whereas in our model incentives follow from pay-for-performance with no threat of termination. Furthermore, in our model it is the firm that has an incentive to renege, not the worker. The main connection between our model and the Becker-Stigler and Shapiro-Stiglitz models is the role of the present value of the ongoing relationship in keeping one of the players honest.

The incentives provided by the implicit contract $(s, b)$ depend on whether the worker "trusts" the firm to honor its implicit commitment to pay the bonus b after observing performance $y=1$. If the worker believes the firm will not renege on the implicit contract, the worker's effort decision from (2.2) is

$$
a *(b)=\frac{b}{2 \gamma}
$$

If salary is set at the minimum value satisfying (2.3), the firm's expected profit per period is

$$
V(b) \equiv a *(b)-\gamma a^{*}(b)^{2}-w_{a}=\frac{b}{2 \gamma}-\frac{b^{2}}{4 \gamma}-w_{a} .
$$

In a single-period employment relationship (or in the final period for a finite-lived firm), the firm will choose not to pay a bonus, so the worker (anticipating the firm's decision) will choose not to supply effort, so the firm (anticipating the worker's choice) does not pay a salary, so the worker chooses not to work for the firm. To formalize the role of trust in enforcing implicit contracts, we consider an infinitely repeated relationship. ${ }^{6}$ We assume that the firm and the worker play trigger strategies: roughly speaking, the parties begin by cooperating and then continue to cooperate unless one side defects, in which case

6 The discount rate $r$ can be reinterpreted so that the game is not infinitely repeated but instead concludes at an uncertain date: suppose that after each period is played a coin is flipped, and that if heads occurs then the gane ends; if the probability of heads is $q$ and the firm's actual discount rate is $s$ then $r=(s+q) /(I-q)$. 
they refuse to cooperate forever after. ${ }^{7}$ Such strategies have the virtue of being simple to analyze but ignore two issues-optimal punishments and renegotiation, both of which are beyond the scope of this paper. 8

We solve for the trigger-strategy equilibrium that maximizes the firm's expected profit. The key issue is how large a bonus the worker can trust the firm to pay. Our assumption that the salary $s$ is base pay and the bonus $b$ is paid only if $y=1$ makes $a$ difference here. The firm's temptation to stiff the worker would be larger if we had no base pay but paid a bonus of $s$ when $y=0$ and a bonus of $b+s$ when $y=1$. On the other hand, the firm's temptation to stiff the worker would be smaller if we had base pay of $s+(b / 2)$ and bonuses of $-b / 2$ when $y=0$ and $b / 2$ when $y=1$. In keeping with observed practice, we assume that the bonus cannot be negative. 9

If the worker's contribution is $y=1$, the firm must decide whether to pay the bonus b. The optimal choice depends on the firm's discount rate, r. Given the worker's strategy, if the firm does not pay the bonus then its payoff is 1 - $s$ this period but zero thereafter, whereas if the firm does pay the bonus then its payoff is $1-s-b$ this period but equal to the expected profit from the relationship thereafter. Thus, the firm should pay the bonus if and

7 More precisely, call the history of play cooperative if the firm has always offered the compensation package $(s, b)$ to be determined below, the worker has always chosen to work for the firm, and the firm has always paid the bonus b when the worker's contribution was $y=1$. The worker's strategy is to work for the firm provided that the history of play is cooperative (choosing alternative employment otherwise), and then to choose the action $a^{*}(b)$ to be determined below. Similarly, the firm's strategy is to offer the compensation package $(s, b)$ provided that the history of play is cooperative (offering $s=b=0$ otherwise), and to pay the bonus $b$ when the worker's contribution is $y=1$ provided that the history of play is cooperative (paying zero bonus otherwise).

8 On optimal punishments: Abreu (1988) shows that the highest equilibrium payoffs are supported by the strongest credible punishments. In our analysis, the punishment for defecting (namely, playing the singleperiod equilibrium forever after) is not the strongest credible punishment. We expect that the qualitative properties of our results would continue to hold in an Abreu-style analysis, because our results hinge on the simple idea that greater cooperation is possible when the value of the ongoing relationship is larger.

On renegotiation: Several authors bave argued that the game that remains after one side defects is identical to the game as a whole, so equilibria available at the beginning of the game should also be available after one side defects, $s 0$ the players should renegotiate from the punishment we propose to a new equilibrium with higher payoffs for both players, thus wrecking our original trigger-strategy equilibrium. Other authors have adopted different perspectives on renegotiation. (See Fudenberg and Tirole (1991. Chapter 5) for a literature review.) Because this literature is still in flux, and especially because the purely game-theoretic analyses of renegotiation abstract from institutions that would influence renegotiation in the labor market, we do not adopt any of the existing approaches to renegotiation.

9 Allowing the bonus to be negative would complicate the analysis by creating a temptation for the worker to stiff the firm, analogous to the firm's temptation we analyze. It may be that the costs of these temptations are convex, so that it is more effective to tempt both sides slightly rather than one side greatly. Our analysis is correct if the firm faces an infinite sequence of workers, each of whom lives for one period (in which case the worker has no reason to resist temptation), and is approximately correct if an infinitely lived worker's discount rate is very large. MacLeod and Malcomson $(1989,1993)$ explore the range of oulcomes that can arise when the present value of the ongoing relationship is divided between the players so as to keep both honest, and also how this division depends on which player can more easily find a substitute for the
other. 
only if the present value of the expected profit beginning next period exceeds the size of the bonus:

$$
\frac{V(b)}{r} \geq b \text {, or } V(b) \geq r b,
$$

where $1 / r$ is the present value of $\$ 1$ received next period and every period thereafter.

The optimal implicit contract sets b to maximize expected profit per period, $V(b)$, subject to the firm's reneging constraint (2.12). Rather than deriving the closed-form solution to the firm's problem, it is more instructive to proceed graphically, as in Panel A of Figure 2.1. The figure plots the firm's expected profit $V(b)$ on the vertical axis and the implicit-contract bonus $b$ on the horizontal axis, and also shows the line $r b$ for various discount rates. For a given value of $r$, values of $b$ where $V(b) \geq r b$ satisfy the reneging constraint and therefore are feasible bonus payments in self-enforcing implicit contracts. Three features of $V(b)$ are intuitive. First, as indicated by (2.11), V(b) is quadratic in $b$. Second, at $b=0,(2.10)$ implies that the worker will not exert effort; so the firm's expected profit per period is $-w_{a}$. Finally, ignoring the reneging constraint, expected profit per period is maximized at $b^{*}=1$, since $a^{*}(1)=1 / 2 \gamma$ is precisely the first-best action, $a^{*}$.

Figure 2.1 illustrates the two primary comparative-static results from this section: the optimal bonus $b^{*}$ decreases as the discount rate or the worker's altemative wage increases;

$$
\frac{\partial b^{*}}{\partial \mathrm{r}}<0, \frac{\partial \mathrm{b}^{*}}{\partial \mathrm{w}_{\mathrm{a}}}<0 \text {. }
$$

Panel A shows that optimal subjective bonuses vary with the firm's discount rate. At sufficiently low discount rates (for example, $r=5 \%$ ), the present value of the ongoing relationship is high so the first-best contract $b^{*}=1$ is feasible. For intermediate values (such as $r=7 \%), b=1$ is not feasible but other values of $b$ satisfy the reneging constraint, so $b^{*}$ is the largest of these feasible values (about .89, as shown in the figure); for such intermediate values of $r$, the optimal bonus falls as $r$ increases. Finally, for sufficiently high discount rates (such as $r=10 \%$ ), no values of $b$ satisfy the reneging constraint, so no implicit contract is feasible. 


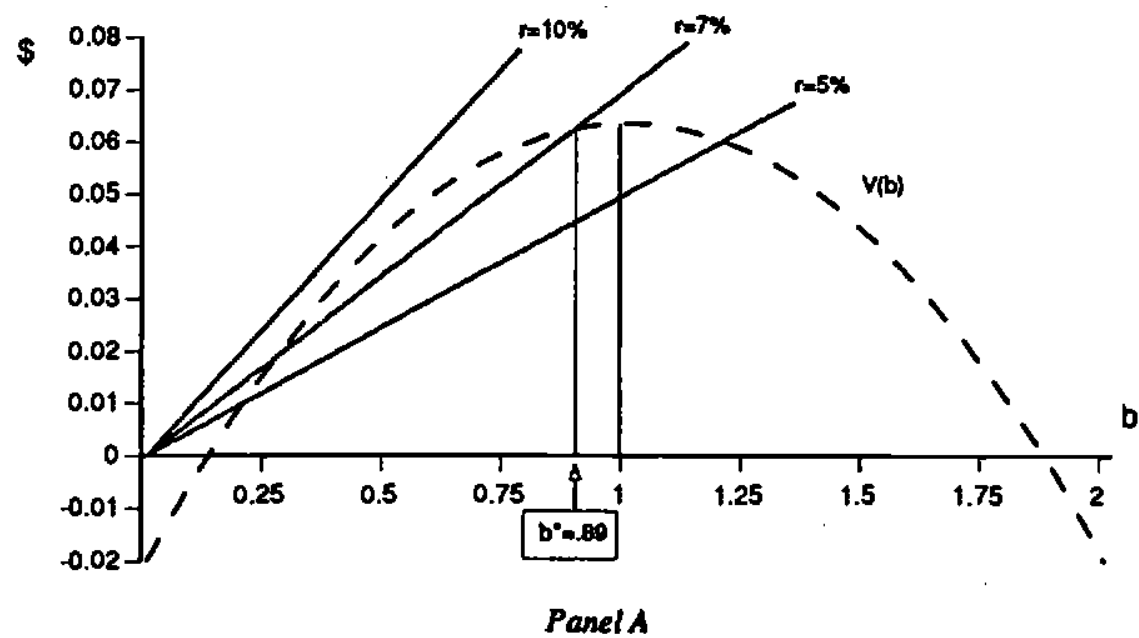

The optimal subjective piece rate declines wish the firm's discount rate.

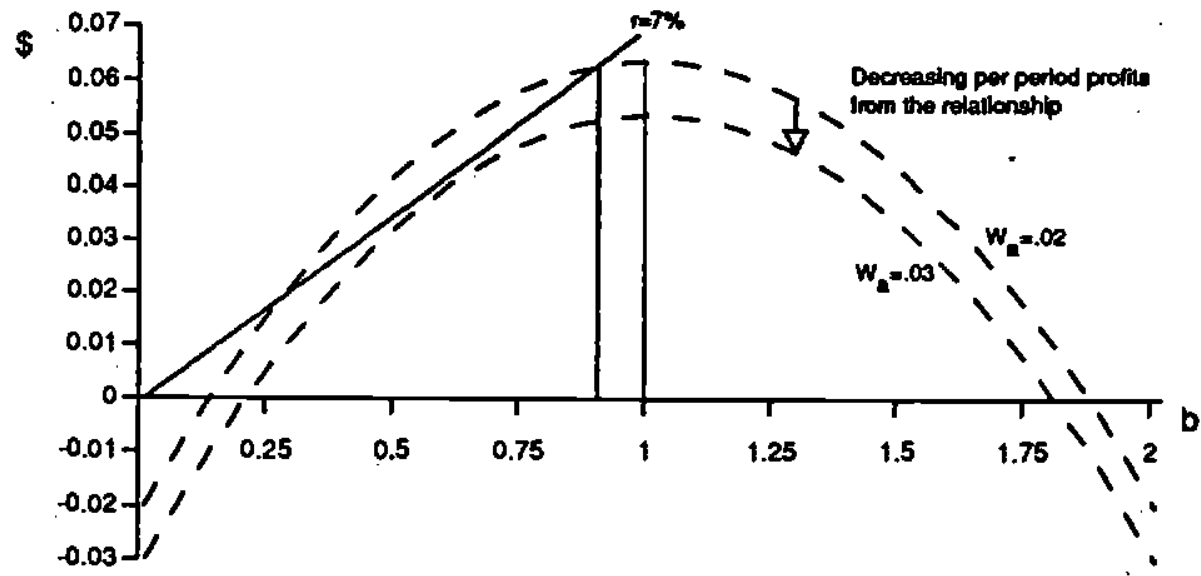

Panel B

The oprimal subjective piece rate declines with the worker's alternative wage.

Nole: The dashed lines are the expected profit per period, V(b) defined by (2.11). The figure assumes $\gamma=3$.

Figure 2.I

Panel B of Figure 2.1 shows that the optimal subjective bonus depends on the worker's alternative wage. As the altemative wage increases (from $w_{a}=.02$ to $w_{a}=.03$ in the figure), the present value of the ongoing relationship falls so the largest feasible (and hence optimal) bonus declines. As illustrated in the figure, for sufficiently high alternative wages, no values of b satisfy the reneging constraint, so no implicit contract is feasible: 


\section{The Optimal Interplay between Implicit and Explicit Contracts}

We can now begin the novel part of the analysis-combining an explicit contract based on an objective performance measure with an implicit contract based on a subjective performance assessment. We assume in Section 3A that the subjective performance assessment is noncontractible but otherwise perfect, in Section 3B we extend the analysis to imperfect subjective performance assessments. Both analyses proceed much as in Section 2C. The major new result (which holds for both perfect and imperfect subjective assessments) is that the choice of an explicit contract now can affect the present value of the ongoing relationship, and hence affect the design and performance of the optimal implicit contract. We also derive several comparative static results.

\section{A. Perfect Subjective Performance Assessments}

At the end of each period, the firm and worker observe the realization of the objective performance measure, $p$, and the realization of the worker's contribution, y. If $p=1$ the firm pays the bonus $\beta$ dictated by the explicit contract, and if $y=1$ the firm chooses whether to pay the worker the bonus b specified in the implicit contract. In Section 2C, the firm's expected profit was V(b) per period if it honored the implicit contract, but zero in all future periods if it reneged on the bonus, since we assumed that the worker would refuse to work for the firm if it reneged. When both objective measures and subjective assessments are available, however, there are new consequences of honoring or reneging on the implicit portion of the contract. First, the expected profit per period from honoring the implicit contract is not $V(b)$ from (2.11) but rather $V(b, \beta)$ from (2.5). Second, when explicit contracts are available, they are available both before and after the firm reneges, so in the latter case it seems natural to assume that the worker would refuse to participate in any future implicit contracts but would be willing to consider explicit contracts, and would accept an explicit contract if it were sufficiently attractive.

In the absence of implicit contracts, the expected profit per period from the optimal explicit contract is $V\left(\beta^{*}\right)$ as defined in (2.9), which can be positive or negative depending on the worker's alternative wage, $w_{a}$, and the level of distortion in the objective performance measure, $\operatorname{var}(\mu)$. As long as $V\left(\beta^{*}\right)>0$, implying that the optimal explicit contract can both attract the worker and make money for the firm, the relevant fallback position for a firm reneging on an implicit contract is $V\left(\beta^{*}\right)$. When this best feasible explicit contract yields negative expected profit, $V\left(\beta^{*}\right)<0$, it is optimal for the firm to shut down rather than enter into this contract, so the relevant fallback position is zero profit. The sign of $V\left(\beta^{*}\right)$ has 
important implications for the optimal interplay between implicit and explicit contracts, so we consider the two cases separately.

Case 1: $V\left(\beta^{*}\right)>0$

We first examine the case where the firm's fallback position is a profitable explicit contract, $V\left(\beta^{*}\right)>0$. Given the payoffs from paying and from not paying the bonus $b$, the firm should honor the implicit contract by paying the bonus if and only if the present value of the difference in expected profit beginning next period exceeds the size of the bonus:

$$
\frac{V(b, \beta)-V\left(\beta^{*}\right)}{r} \geq b \text {, or } V(b, \beta)-V\left(\beta^{*}\right) \geq r b
$$

Assuming that the reneging constraint (3.1) is satisfied, the worker's effort decision a* $(\mu, b$, ß) is given by (2.2).

The optimal contract sets $b$ and $\beta$ to maximize expected profit $V(b, \beta)$, subject to the reneging constraint (3.1). Defining $\lambda$ as the Lagrange multiplier for (3.1), and using (2.2), (2.5), and (2.9), the first-order conditions for the optimal contract involving both subjective assessments and objective measures (i.e., when $b>0$ and $\beta>0$ ) are:

$$
\begin{aligned}
& (1+\lambda) \cdot(1-b-\beta)=2 \lambda \gamma, \\
& (1+\lambda) \cdot\left(1-b-\beta \cdot E_{\mu}\left(\mu^{2}\right\}\right)=0 .
\end{aligned}
$$

We denote the optimal bonuses as $b^{* *}$ and $\beta^{* *}$, to distinguish them from (and compare them to) the optimal implicit contract $b *$ in Section $2 C$ and the explicit contract $\beta^{*}$ in Section $2 B$.

Equation (3.2b) yields the optimal $\beta$ given an arbitrary value of $b$, which we denote $\beta * *(b):$

$$
\beta^{* *}(b)=(1-b) \cdot \frac{1}{1+\operatorname{var}(\mu)}=(1-b) \cdot \beta^{*} .
$$

That is, the optimal $\beta$ when explicit and implicit contracts are combined is the optimal $\beta$ for an explicit contract alone in the incentive problem of size ( 1 - b) that remains once an implicit contract with bonus $b$ is in effect. One intuitive implication of (3.3) is that if $b^{* *}$ is near one then $\beta^{* *}$ is near zero: if an implicit contract alone nearly achieves the first-best then there is not much need for an explicit contract based on an imperfect performance measure.

For parameter values such that the first-best implicit contract $b^{* *}=1$ is not feasible, the optimal $b^{* *}$ is determined by substituting $\beta^{* *(b)}$ into the reneging constraint (3.1). Using equations (2.2), (2.5), and (2.9), the reneging constraint reduces to

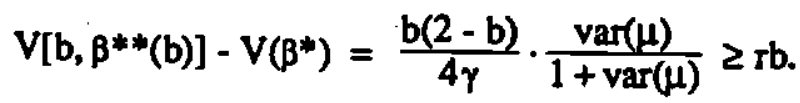


The optimal implicit-contract bonus $b^{* *}$ is then the largest value of $b$ solving (3.4). Thus,

$$
b^{* *}= \begin{cases}1 & \text { for } 4 \gamma<\frac{\operatorname{var}(\mu)}{1+\operatorname{var}(\mu)}, \\ 2-4 \gamma \frac{1+\operatorname{var}(\mu)}{\operatorname{var}(\mu)} & \text { for } \frac{1}{4}\left(\frac{\operatorname{var}(\mu)}{1+\operatorname{var}(\mu)}\right) \leq \gamma r \leq \frac{1}{2}\left(\frac{\operatorname{var}(\mu)}{1+\operatorname{var}(\mu)}\right), \\ 0 & \text { for } 2 \gamma r>\frac{\operatorname{var}(\mu)}{1+\operatorname{var}(\mu)} .\end{cases}
$$

Equation (3.5) implies that implicit contracts cannot be used $\left(b^{* *}=0\right.$ ) when the discount rate is sufficiently high and/or the level of distortion in the objective performance measure is sufficiently low. The intuition behind the former result is clear from Section $2 \mathrm{C}$. The intuition behind the latter is more interesting: if objective performance measures are sufficiently close to perfect then the firm's fallback position after reneging on an implicit contract is too attractive - the firm will renege on any implicit contract. That is, even though explicit contracts are not perfect, they can be sufficiently effective that they vitiate implicit contracts, forcing the parties to transact in spot-market rather than long-term relationships. In this sense, strong but imperfect performance in spot-market transactions actually hinders (in fact, destroys) attempts to use implicit contracts as well.

Similarly, the first-best $\left(b^{* *}=1\right)$ can be achieved at sufficiently low discount rates, but the highest discount rate at which the first-best can be achieved declines as var( $\mu)$ falls. Even for a very low discount rate, the first-best cannot be achieved when the objective performance measure is nearly perfect and so the fallback contract itself is nearly first-best.

For intermediate values of the optimal implicit-contract bonus $\left(0<b^{* *}<1\right)$, the optimal implicit-contract bonus increases as the objective performance measure becomes more distortionary ( $\operatorname{var}(\mu)$ increases), and (3.3) then implies that the optimal explicit-contract bonus $\beta^{* *}$ decreases as $\operatorname{var}(\mu)$ increases. Likewise, as $\mathrm{r}$ falls $b^{* *}$ rises, so $\beta^{* *}$ falls. These results confirm the intuition that implicit and explicit contracts can be substitutes.

One important difference between $b^{* *}$ and $b^{*}$ (the optimal implicit contract in the absence of explicit contracts, analyzed in Section $2 C$ ) is that $b^{*}$ depends on (and declines with) the alternative wage $w_{a}$, while $b^{* *}$ in (3.5) is independent of $w_{a}$. This difference reflects differences in the fallback position from reneging on the implicit contract. In Section $2 \mathrm{C}$, in the absence of explicit contracts, the employment relationship ended if the firm reneged on an implicit contract, so the firm had to meet the worker's alternative wage after honoring an implicit contract but not after reneging. When $V\left(\beta^{*}\right)>0$, however, the firm 
must meet the worker's alternative wage both after honoring the implicit contract and after reneging on it, so the net cost of reneging in (3.1) is independent of the alternative wage.

To summarize, (3.5) and (3.3) yield the following six comparative-static results: when $V\left(\beta^{*}\right)>0$ (and for parameters such that $0<b^{* *}<1$ ),

$$
\begin{aligned}
& \frac{\partial b^{* *}}{\partial \mathrm{r}}<0, \frac{\partial b^{* *}}{\partial w_{a}}=0, \frac{\partial b^{* *}}{\partial \operatorname{var}(\mu)}>0, \\
& \frac{\partial \beta^{* *}}{\partial \mathrm{r}}>0, \frac{\partial \beta^{* *}}{\partial w_{a}}=0, \frac{\partial \beta^{* *}}{\partial \operatorname{var}(\mu)}<0 .
\end{aligned}
$$

Case 2: $V\left(\beta^{*}\right)^{\prime}<0$

We now examine the alternative case, in which the firm's fallback position after reneging on an implicit contract is to shut down and earn zero profit thereafter. This shutdown fallback occurs when the expected profit from the optimal explicit contract in the absence of implicit contracts is negative, $V\left(\beta^{*}\right)<0$. We can also imagine circumstances in which reneging on an implicit contract precludes the firm not only from entering into implicit contracts in the future but also from entering into effective explicit contracts in the future. ${ }^{10}$ The results in this subsection apply whenever the relevant fallback is to shut down.

When $V\left(\beta^{*}\right)<0$, the reneging constraint is not $V(b, \beta)-V\left(\beta^{*}\right) \geq$ rb as in (3.1) but rather $V(b, \beta) \geq \mathrm{rb}$. Solving for the optimal contract proceeds as above; the only difference is in the reneging constraint. As shown in the Appendix, the first-order conditions (3.2a) and (3.2b) continue to hold for this new problem, as does the expression for $\beta^{* *}(b)$ in equation (3.3). The reneging constraint can therefore be written as $V\left[b, \beta^{* *}(b)\right] \geq r b$, from which it is straightforward to derive the first five of the following six comparative-static results: when $V\left(\beta^{*}\right)<0$ (and for parameters such that $0<b^{* *}<1$ ),

$$
\begin{aligned}
& \frac{\partial b^{* *}}{\partial \mathrm{r}}<0, \frac{\partial \mathrm{b}^{* *}}{\partial w_{\mathrm{a}}}<0, \frac{\partial b^{* *}}{\partial \operatorname{var}(\mu)}<0, \\
& \frac{\partial \beta^{* *}}{\partial \mathrm{r}}>0, \frac{\partial \beta^{* *}}{\partial w_{\mathrm{a}}}>0, \frac{\partial \beta^{* *}}{\partial \operatorname{var}(\mu)} \stackrel{>}{\gtrless} .
\end{aligned}
$$

The derivations of these comparative-static results are relegated to the Appendix. Here we compare these results to those from the first case, $V\left(\beta^{*}\right)>0$.

10 Although such issues are beyond the scope of our model, multi-period explicit contracts in practice have important subjective components (such as implicit understandings not to "ratchet" the piece rate or performance target over time) that require employer-employee trust. Breaking implicit contracts in these situations may affect the effectiveness or even the feasibility of future explicit contracts: it may be impossible for the firm to fall back to $V\left(\beta^{*}\right)$; the relevant alternative may be to shut down. 
Recall that when $V\left(\beta^{*}\right)>0$, an increase in the discount rate reduces the largest feasible implicit-contract bonus, and (3.3) then implies that the optimal explicit-contract bonus increases. These two results reappear when the relevant fallback position is to shut down. Similarly, recall from Section $2 \mathrm{C}$ (i.e., in the absence of explicit contracts) that an increase in the alternative wage $w_{a}$ reduces the present value of the ongoing employment relationship, so the implicit-contract bonus falls. This result also reappears when the relevant fallback position is to shut down, and here, in the presence of explicit contracts, (3.3) again implies that the explicit-contract bonus increases.

The most interesting comparative-static results in (3.7) involve changes in $\operatorname{var}(\mu)$, the level of distortion of the objective performance measure. Recall that when $V\left(\beta^{*}\right)>0$, decreasing the distortion in the objective performance measure increases the explicit bonus and decreases the implicit bonus-implicit and explicit contracts are substitutes. When $V\left(\beta^{*}\right)$ $<0$, however, the implicit bonus $b^{* *}$ increases as the objective performance measure becomes less distortionary, while the effect on the explicit bonus $\beta^{* *}$ is ambiguous. The intuition behind these results is as follows.

Suppose that the worker and firm are currently engaged in the optimal implicit contract in the absence of explicit contracts- $b^{*}$, as derived in Section $2 \mathrm{C}$ - earning expected profit $V\left(b^{*}\right)>0$. Suppose further that the discount rate is sufficiently high that this implicit contract is second best $\left(b^{*}<1\right)$, so that the reneging constraint $(2.12)$ is binding: $V\left(b^{*}\right)=r b^{*}$. Now consider the introduction of an imperfect objective performance measure, but suppose that $p$ is sufficiently distortionary that it could not support a profitable explicit contract in the absence of implicit contracts-that is, $V\left(\beta^{*}\right)<0$. Even though $p$ is not profitable on its own, setting a low piece rate $\beta$ can improve expected profit, holding $b$ constant: $V\left(b^{*}, \beta\right)>V\left(b^{*}\right)$ for small values of $\beta$. This increase in the present value of the ongoing employment relationship implies that the reneging constraint is no longer binding, $V\left(b^{*}, \beta\right)>r^{*}$, which in turn implies that the implicit bonus $b^{* *}$ can be increased from its optimal value in the absence of explicit contracts, $b^{* *}>b^{*}$. Thus, the objective performance measure enhances the effectiveness of subjective performance assessment by increasing the value of the ongoing relationship between the firm and the worker, thereby decreasing the firm's incentive to renege on an implicit contract and so increasing the reliance on subjective assessments.

The result that introducing objective performance measures increases the value of the ongoing relationship, thereby allowing the increased the use of implicit contracts, also holds for improvements in existing objective measures: as long as $V\left(\beta^{*}\right)$ remains negative, decreases in $\operatorname{var}(\mu)$ improve the value of the relationship and so cause the optimal bonus $b^{* *}$ to increase. Equation (3.3) suggests why the effect of changes in $\operatorname{var}(\mu)$ on $\beta^{* *}$ is 
ambiguous: both $b^{* *}$ and $1 /(1+\operatorname{var}(\mu))$ increase when $\operatorname{var}(\mu)$ declines, so the net implication for $\beta^{* *}$ is unclear. It is not difficult to construct examples in which $\beta^{* *}$ is non-monotone in $\operatorname{var}(\mu)$.

Figure 3.1 illustrates how implicit and explicit contracts vary with the level of distortion in the objective performance measure. The figure assumes a discount rate $r=8 \%$, an alternative wage $w_{a}=.02$, and an effort-disutility parameter $\gamma=3$. The top panel of the figure shows the optimal explicit contract in the absence of implicit contracts ( $\beta^{*}$ from Section 2B) and the optimal implicit contract in the absence of explicit contracts (b* from Section $2 C)$. Naturally, variations in $\operatorname{var}(\mu)$ have no effect on the optimal implicit contract $b^{*}$. As $\operatorname{var}(\mu)$ approaches zero, $\beta^{*}$ approaches one, since then $p$ is identical to $y$ and the optimal explicit contract can achieve the first-best. At sufficiently high distortions (i.e., $\operatorname{var}(\mu)>19 / 6$, given the other parameter assumptions), the best explicit contract in the absence of implicit contracts is unprofitable, $V\left(\beta^{*}\right)<0$.

The bottom panel of Figure 3.1 considers optimal implicit and explicit contracts when the two are used together $\left(b^{* *}\right.$ and $\left.\beta^{* *}\right)$. For sufficiently small var $(\mu)$, no implicit contract is feasible because the firm's fallback position is too attractive, so the optimal contract is simply the explicit contract $\beta^{*}$. The optimal implicit-contract bonus $b^{* *}$ becomes positive once the distortion in the objective performance measure makes the firm's fallback position sufficiently unattractive: $V\left[b, \beta^{* *}(b)\right]-V\left(\beta^{*}\right)>$ rb for small values of $b$. Equation (3.5) shows that $b^{* *}>0$ when $\operatorname{var}(\mu)>2 \gamma t /(1-2 \gamma t)$ (or $\operatorname{var}(\mu)>12 / 13$, given the assumed parameters). This critical value of $\operatorname{var}(\mu)$ is denoted by $V\left(b^{* *}, \beta^{* *}\right)-V\left(\beta^{*}\right)=r b^{* *}$ in the figure. Increases in the distortion of $p$ past this critical value result in increases in $b^{* *}$ and further decreases in $\beta^{* *}$, both because higher implicit bonuses can be supported as the fallback position becomes less attractive, and because $p$ becomes less useful as a performance measure.

A second critical value of $\operatorname{var}(\mu)$ is denoted $V\left(\beta^{*}\right)=0$, as defined in the top panel. For all values of $\operatorname{var}(\mu)$ above (and for some values below) this second critical value, the optimal implicit bonus $b^{* *}$ exceeds the bonus $b^{*}$ from the optimal implicit contract in the absence of explicit contracts, because the use of $\beta^{* *}>0$ enhances the value of the ongoing relationship and so allows increased reliance on the subjective performance assessment. 

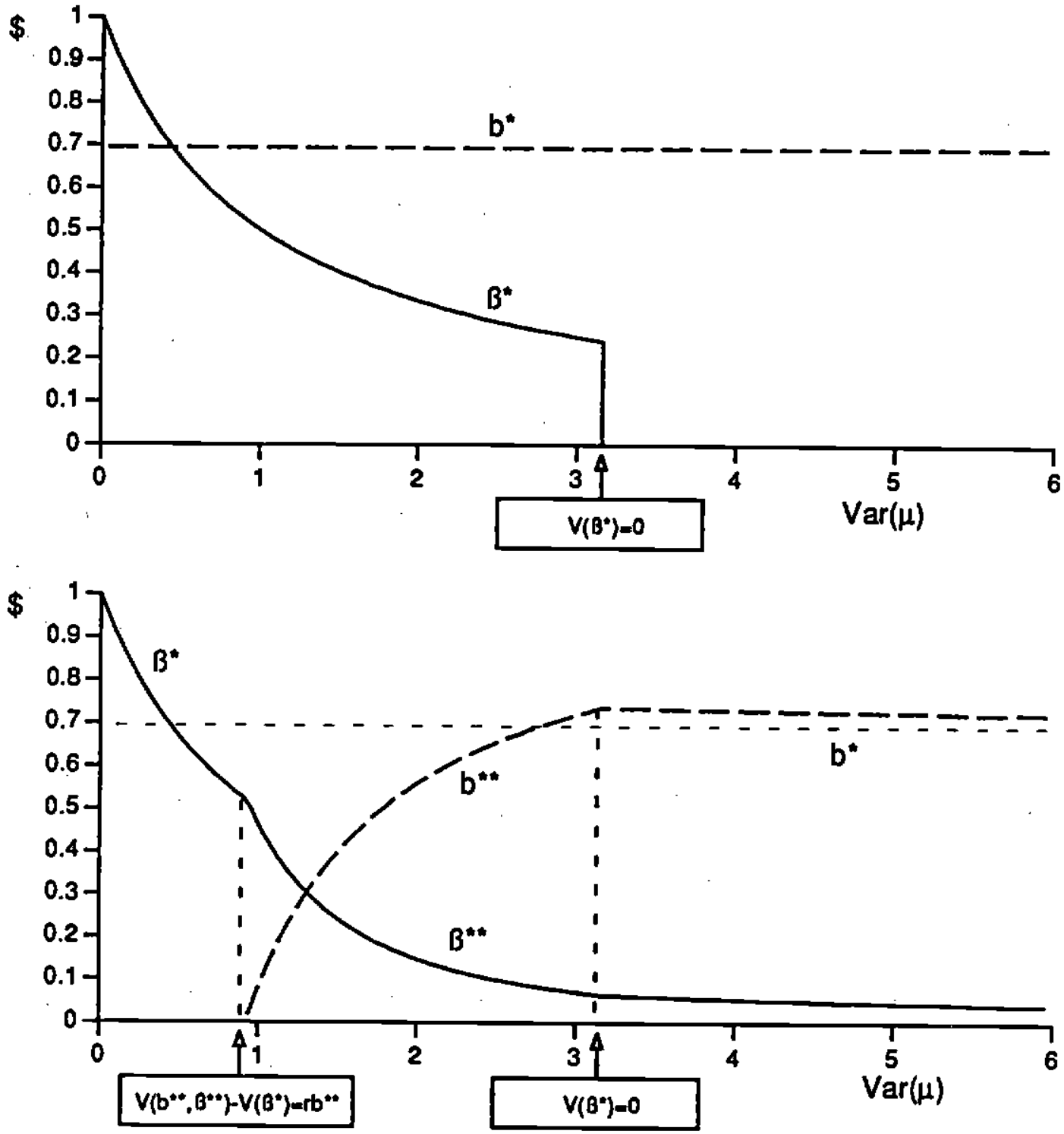

Note: $b^{*}$ is the bonus for an implicit contract in the absence of any explicit contract, $\beta^{*}$ is the bonus for an explicit contract if no implicit contract is used, and $b^{* *}$ and $\beta^{* *}$ are the implicit and explicit bonuses when the two contracts are used in combination. The figure assumes $w_{a}=.02$, $r=8 \%$, and $\gamma=3$.

\section{Figure 3.1}

Figure 3.2 provides a more striking illustration of the extent to which implicit and explicit contracts can reinforce each other. As Figure 2.1 illustrated. for sufficiently high values of $r$ or $w_{a}$, no implicit contract is feasible on its own-no value of $b$ generates enough profit to stop the firm from reneging. Likewise, if the variance of $\mu$ is sufficiently large then no explicit contract is feasible on its own-V( $\left.\beta^{*}\right)<0$. If the variance of $\mu$ is not too large, 


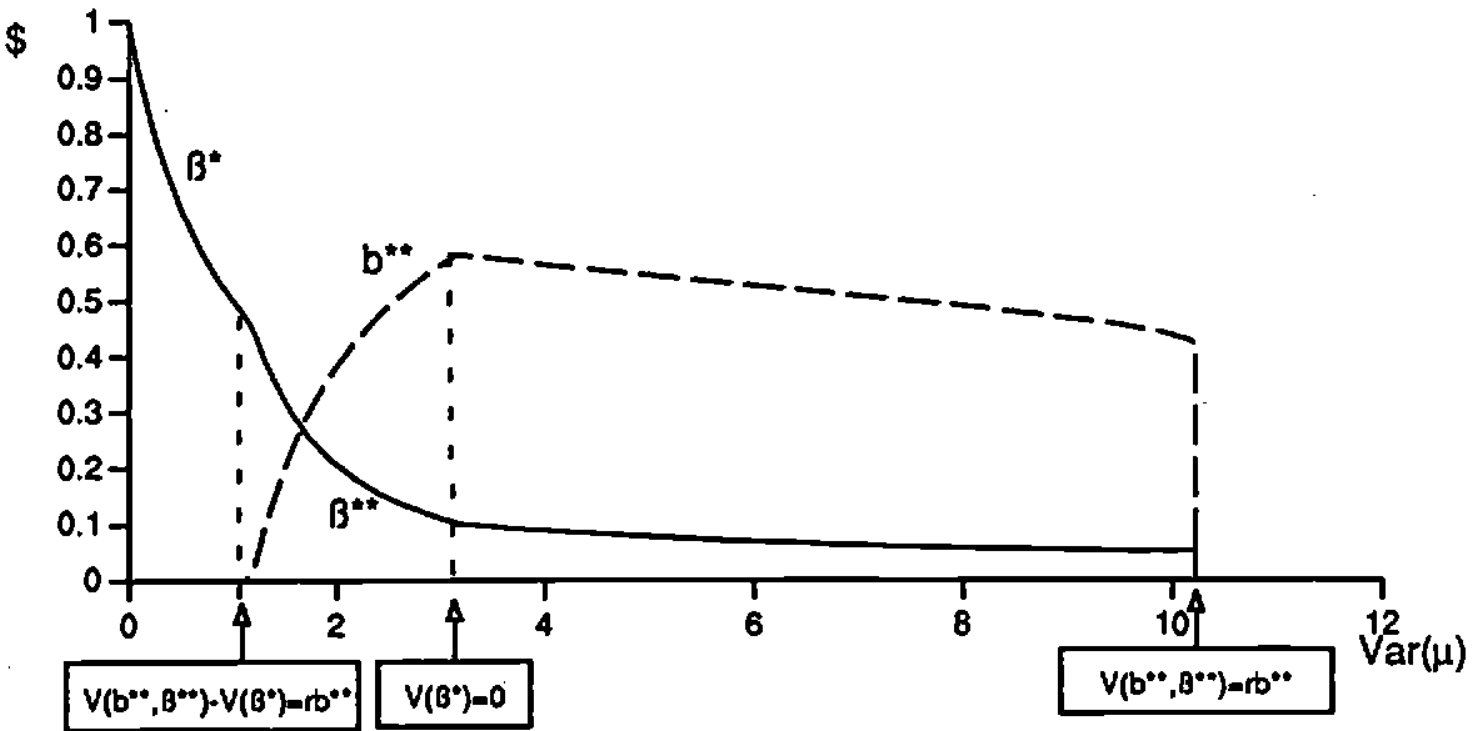

Note: The figure assumes $w_{a}=.02, r=9 \%, \gamma=3$. In this case, no implicit contract is feasible on its own, so $b^{*}$ is not defined. If var(1) $>10.3$, implicit contracts are infeasible even in combination with the optimal explicit contract, so $b^{* *}$ is undefined.

\section{Figure 32}

however, then it may be that implicit and explicit contracts can operate in combination even though neither is feasible alone.

The parameters underlying Figure 3.2 are the same as assumed in Figure 3.1, except that the discount rate has been increased to $9 \%$-sufficiently high that no implicit contract is feasible on its own. (Note that the scale of the figure differs from Figure 3.1.) As before, $w_{\mathrm{a}}=.02$ and $\gamma=3$, so no explicit contract is feasible on its own when $\operatorname{var}(\mu) \geq 19 / 6$. Nonetheless, for a substantial range of values of $\operatorname{var}(\mu)$ above $19 / 6$, implicit and explicit contracts are feasible if (but only if) used in combination.

\section{B. Imperfect Subjective Performance Assessments}

In Sections $2 \mathrm{C}$ and $3 \mathrm{~A}$ we assumed that the firm and the worker both were able to observe a perfect measure of the worker's contribution to firm value $(y)$ that could be the basis of an implicit contract, but not an explicit one. In this subsection, we relax this assumption: we assume that one or both of the parties cannot observe $y$, so implicit contracts like those in Sections $2 \mathrm{C}$ and $3 \mathrm{~A}$ are not possible. We also assume, however, that both parties can observe a new subjective performance measure, $q$, that is an imperfect proxy for $y$ in the same way that $p$ is (as explained below). In this section, we sketch our model and describe the primary results and intuition behind our analysis. The formal derivations of these results are available from the authors upon request. 
We interpret $q$ as representing performance evaluation by immediate supervisors. The imperfections in $q$ as a proxy for $y$ could reflect the supervisor's inability or bias in assessing local aspects of the subordinate's performance; alternatively, local performance could be assessed perfectly but firm-wide performance imperfectly. The worker may be able to exploit suspected biases in the supervisor's evaluation technology, by focusing on actions that are perceived favorably by the supervisor regardless of their effects on the value of the organization. This possibility suggests the value of performance evaluation by multiple supervisor, which we discuss in Section 6.

Formally, we assume that $q$ equals either zero or one, and that $q=1$ with probability $\varepsilon \cdot a$, where $\varepsilon$ is a strictly positive random variable with $E\{\varepsilon\}=1$. Similar to our assumptions on $\mu$, we assume that: the support of $\varepsilon$ and the value of $\gamma$ are such that $\varepsilon \cdot a<1 ; \varepsilon$ and $\mu$ are independent; and given $\varepsilon, \mu$, and $a$, the events that $q=1, p=1$, and $y=1$ are independent. A worker paid on the basis of the subjective and objective performance measures $q$ and $p$ observes $\varepsilon$ and $\mu$ (neither of which is observed by the firm) and then chooses an action. Thus, the only qualitative difference between $q$ and $p$ is that the former is subjective and so cannot be the basis of an explicit contract.

The primary results from Section $3 \mathrm{~A}$ continue to hold for imperfect subjective performance measures. In particular, explicit contracts can enhance the performance of imperfect implicit contracts by increasing the value of the ongoing relationship between the firm and the worker, and thereby decreasing the firm's incentive to renege on an implicit contract. To emphasize that the subjective performance measure is $q$ rather than $y$, we will write $B$ rather than $b$ for the bonus paid in the implicit contract. In this notation, the above result can be stated as $\mathrm{B}^{* *}>\mathrm{B}^{*}$.

In addition to reinvestigating the results derived in Section $3 \mathrm{~A}$, we also analyzed the effects of increasing the distortion associated with the subjective assessment (modeled as increases in the variance of $\varepsilon$ ). Not surprisingly, as the subjective measure becomes increasingly distortionary, the optimal size of the implicit-contract bonus $\left(\mathrm{B}^{* *}\right)$ decreases and the optimal size the explicit-contract bonus $\left(\beta^{* *}\right)$ increases:

$$
\frac{d B^{* *}}{d \operatorname{var}(\varepsilon)} \leq 0, \frac{d \beta^{* *}}{d \operatorname{var}(\varepsilon)} \geq 0
$$

Simply put, as the accuracy of the implicit performance measure goes down, less use will be made of implicit contracts, and more use will be made of explicit ones. 


\section{Subjective Weights on Objective Performance Measures}

The explicit contracts analyzed in Sections $2 \mathrm{C}$ and 3 induced the worker's effort supply to be an increasing function of $\mu$, but the first-best action $\left(a^{*}=1 / 2 \gamma\right)$ is independent of $\mu$. For the optimal explicit contract in the absence of implicit contracts, $\beta^{*}=1 /(1+\operatorname{var}(\mu))$ from (2.8), for example, the worker will work harder than socially optimal when $\mu>(1+$ $\operatorname{var}(\mu))$, and will work less hard than socially optimal when $\mu<(1+\operatorname{var}(\mu))$. The worker "games" the compensation system by taking actions that achieve higher bonuses, even when these actions do not maximize the value of the firm.

In this section, we assume that the employer or a supervisor can subjectively assess the incentive distortions caused by the imperfect objective performance measure. In particular, we assume not only that the worker observes $\mu$ before choosing an action (as before) but now also that the firm observes $\mu$ after $p$ is realized. If the employer's observation of $\mu$ were contractible then the first-best could be achieved by setting a $\mu$ contingent piece rate of $\beta(\mu)=1 / \mu$. This explicit contract would equate the expected marginal products of the worker's action on $y$ and $p$ for all values of $\mu$, thus eliminating all incentive distortions. We assume, however, that $\mu$ is noncontractible (or "subjective," in the sense in which we applied the term to the performance assessments $y$ and $q$ ).

When the employer's observation of $\mu$ is noncontractible, it can be used only as part of an implicit contract enforced through the firm's reputation concerns. In our analysis of such subjective weights on objective performance measures (or "subjective piece rates," for short), we assume as before that the worker receives a base salary, $s$, and a bonus for achieving $p=1$. The total bonus is $\beta+b(\mu)$, including both a non-negative objective component, $\beta \geq 0$, and a non-negative subjective component, $b(\mu) \geq 0$. Since $\mu$ is noncontractible, $\beta$ cannot be contingent on $\mu$, but the implicit-contract bonus $b(\mu)$ can vary with $\mu$.

In order to focus on subjective weights on objective measures, in this section we ignore subjective weights on subjective measures-that is, we ignore implicit contracts based on $y$ or $q$, as were analyzed earlier. If the worker believes that the firm will honor the implicit contract $b(\mu)$, the worker's problem (after observing $\mu$ ) is therefore

$$
\max _{a} s+\mu \cdot a \cdot[\beta+b(\mu)]-c(a),
$$

so the worker's optimal action is 


$$
a^{*}[\mu, \beta, b(\mu)]=\frac{\mu(\beta+b(\mu)]}{2 \gamma}
$$

As in our earlier analyses of implicit contracts based on $y$, the first-best can be achieved here if the discount rate is sufficiently low. To achieve the first-best the firm must pay a total bonus of

$$
\beta+b(\mu)=\frac{1}{\mu}
$$

for each possible value of $\mu$. If the firm honors this implicit contract (by paying the subjective piece rate $b(\mu)$ on the objective performance measure $p)$, it will receive the firstbest profit thereafter-namely, $V_{p b}=1 /(4 \gamma)-w_{a}$. If the firm reneges it will thereafter receive the profit from the optimal explicit contract-namely, $V\left(\beta^{*}\right)=1 / 4 \gamma(1+v a r(\mu))-w_{a}$ from (2.9). The firm thus will honor the first-best contract defined by (4.3) if and only if the present value of the difference in expected profit beginning next period exceeds the size of the bonus:

$$
b(\mu) \leq \frac{V_{f b} \cdot V\left(\beta^{*}\right)}{r} \text { for all } \mu
$$

or, equivalently,

$$
\frac{1}{\mu}-\beta \leq \frac{1}{14 \gamma}\left(\frac{\operatorname{var}(\mu)}{1+\operatorname{var}(\mu)}\right) \text { for all } \mu \text {. }
$$

As (4.5) shows, the firm is most tempted to renege after observing low realizations of $\mu$, since these realizations require high subjectively determined bonuses. A sufficient condition for achieving the first-best is for (4.5) to hold at $\beta=0$ for the lowest possible $\mu$, which we denote by $\mu_{L}>0$. If this sufficient condition fails, the firm may still be able to achieve the first-best by combining implicit and explicit contracts, as follows.

Denoting the highest value of $\mu$ by $\mu_{\mathrm{H}}$, the highest possible $\beta$ consistent with the firstbest is $\beta=1 / \mu_{\mathrm{H}}$, since any higher objective piece rate would require a negative subjective piece rate over some range of $\mu$ (which in turn might induce workers to renege on the implicit contract, as discussed in footnote 9). We will call $\beta_{\mathfrak{B b}}=1 / \mu_{H}$ the first-best objective piece rate. To achieve the first-best, the subjective piece rate, $b(\mu)$, must be $b_{f b}(\mu)=1 / \mu-\beta_{f b}$, so that total incentives are $\beta_{\mathrm{fb}}+b_{\mathrm{bb}}(\mu)=1 / \mu$ for each $\mu$ : the subjective piece rate completely eliminates or "backs out" the distortions that would be inherent in any objective piece-rate contract. This combination of implicit and explicit contracts- $b_{\mathfrak{f b}}(\mu)$ and $\beta_{\mathfrak{f b}}$-is illustrated by the bold curve in Figure 4.1.

Although this first-best contract is feasible at sufficiently low discount rates, it is not feasible when discount rates are too high, because the firm finds it worthwhile to renege on 
the largest subjectively determined bonuses (which are associated with the smallest values of $\mu)$. If we (temporarily) fix the objective piece rate at its first-best level, $\beta_{f b}=1 / \mu_{H}$, then we can define $\mu_{\mathrm{L}}^{*}>\mu_{\mathrm{L}}$ as the lowest value of $\mu$ that satisfies (4.5). That is, $\mu_{\mathrm{L}}{ }^{*}$ solves

$$
\frac{1}{\mu_{L}^{*}} \equiv \frac{1}{\mathrm{r} 4 \gamma}\left(\frac{\operatorname{var}(\mu)}{1+\operatorname{var}(\mu)}\right)+\beta_{\mathrm{fb}} \text {. }
$$

One feasible contract is to set the objective piece rate at $\beta_{f b}$ and the subjective piece rate at $b(\mu)=1 / \mu-\beta_{f b}$ for $\mu \geq \mu_{L}^{*}$ and $b(\mu)=1 / \mu_{L}^{*}-\beta_{f b}$ for $\mu<\mu_{L}^{*}$. (This contract is depicted in Figure 4.1 as the bold first-best contract for $\mu \geq \mu_{L}^{*}$ and the bold dashed line at $1 / \mu_{\mathrm{L}}{ }^{*}$ for $\mu<\mu_{\mathrm{L}}^{*}$.) This feasible contract will provide first-best incentives for $\mu \geq \mu_{\mathrm{L}}$, but will not induce optimal effort for low realizations of $\mu$.

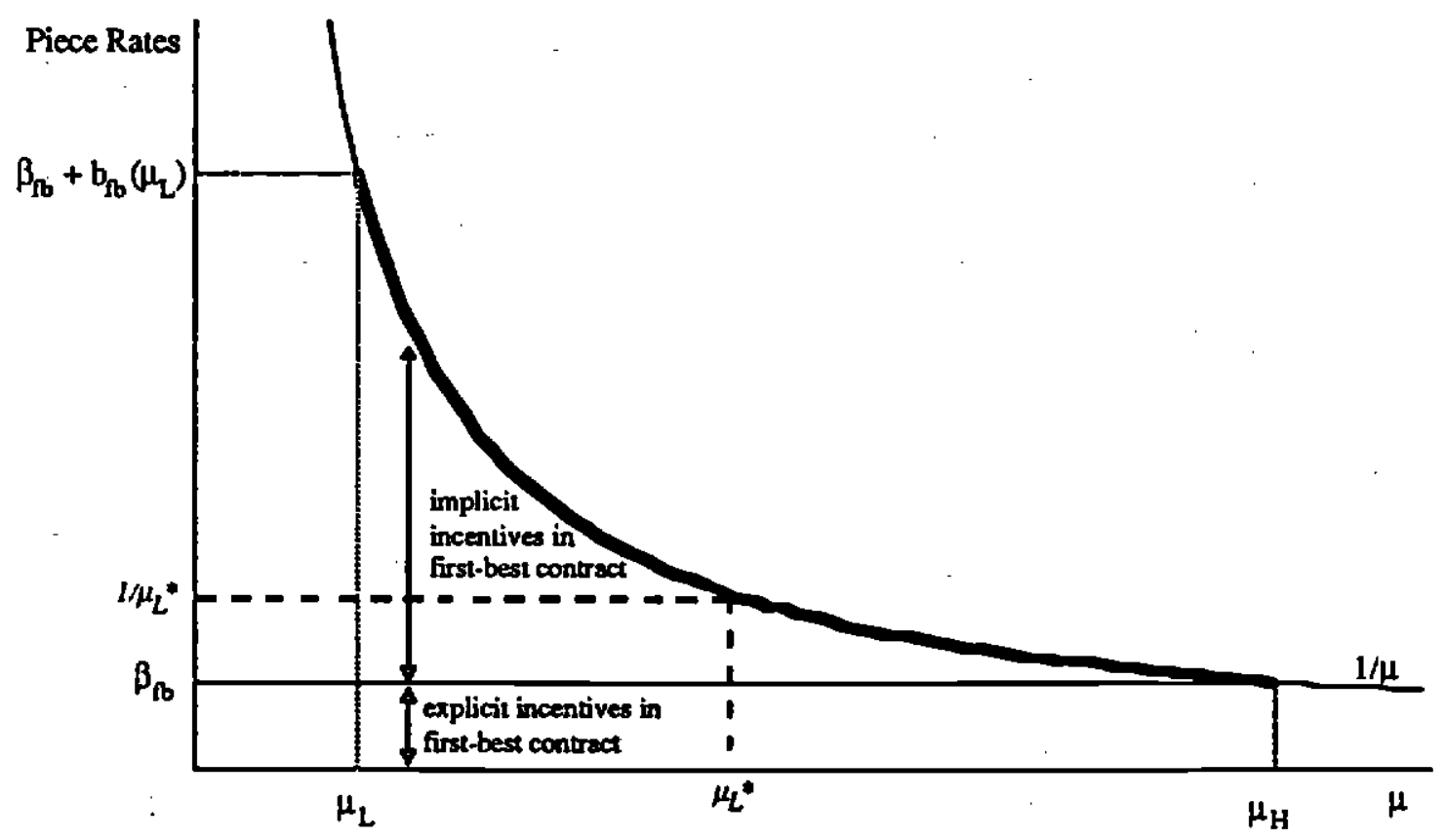

Figure shows the first-best combination of explicit and implicit weights on the objective performance measure (bold curve), as well as the maximum feasible total incentives associated with first-best explicit incentives (bold dashed line). See text for definition of variables.

\section{Figure 4.1}

The envelope theorem implies that this feasible contract can be improved by setting the objective piece rate $\beta$ above its first-best value. Consider the effects of a small increase in the explicit piece rate to some $\beta>\beta_{\mathrm{fb}}$. First, total incentives for the highest levels of $\mu$ will be too high, leading to departures from first-best actions. Since $\beta_{\mathrm{fb}}$ provided first-best incentives for these highest values of $\mu$, however, this change is second-order. The second effect of increasing $\beta$ is to increase total incentives for all values of $\mu$ less than $\mu_{L}{ }^{*}$ (so far holding $b(\mu)$ fixed specified above). Since total incentives were below the first-best level for 
all $\mu<\mu_{\mathrm{L}}^{*}$, this increase in total incentives is a first-order effect. Indeed, this first-order gain will increase expected profits and so allow the firm to increase $b$ for low values of $\mu$, further increasing the total incentives in this region.

By the preceding argument, the second-best contract (illustrated in Figure 4.2) sets $\beta_{s b}>\beta_{f b}$, providing too much incentive for high realizations of $\mu$, and too little incentive for low values of $\mu$. The second-best contract will involve two critical values of $\mu$, denoted by $\mu_{\mathrm{L}}$ sb and $\mu_{\mathrm{H}}{ }^{\mathrm{sb}}$, where $\mu_{\mathrm{L}}<\mu_{\mathrm{L}}{ }^{\mathrm{sb}} \leq \mu_{\mathrm{H}}{ }^{\mathrm{sb}}<\mu_{\mathrm{H}}$. For values of $\mu<\mu_{\mathrm{L}}$, the firm will suffer inadequate incentives but will not renege on its implicit contract; for values of $\mu>\mu_{\mathrm{H}^{\text {st }}}$, the firm will suffer excessive incentives, because $\beta_{8 b}=1 / \mu_{\mathrm{K}}{ }^{\mathrm{sb}}>\beta_{\mathrm{fb}}$. The subjective weight on the performance measure is given by:

$$
b_{s b}(\mu)= \begin{cases}0 & \text { for } \mu \geq \mu_{H} s b \\ 1 / \mu_{L}-\beta_{s b} & \text { for } \mu_{L} s b<\mu<\mu_{H} s b \\ 1 / \mu_{L} s b-\beta_{s b} & \text { for } \mu \leq \mu_{L}^{s b} .\end{cases}
$$

In this analysis of subjective weights on objective performance measures, subjective weights allow the employer to mitigate known or suspected distortions in the performance measurement process. To do so, the contract between the worker and the firm is left deliberately vague: although there is an explicit understanding of how performance is measured, there is only an implicit understanding regarding how that performance measure is rewarded. There is an important role for objective weights in this contract, because increasing the objective piece rate reduces the firm's temptation to renege on the subjective portion. Objective weights that do not distort incentives will always be preferred to subjective weights; the envelope theorem implies that the firm will accept some degree of distorted incentives for an increased ability to enter into implicit contracts. 


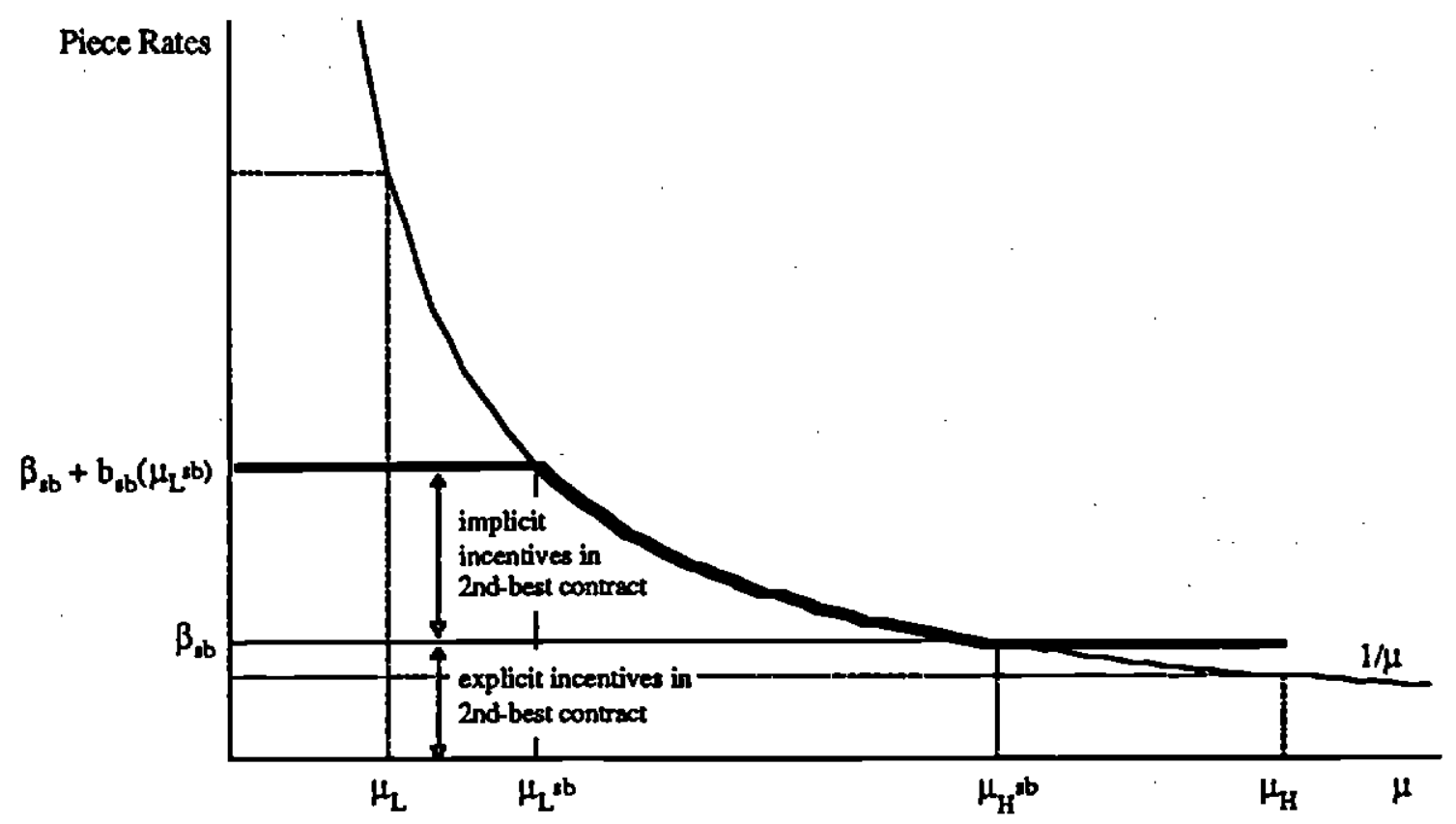

Figure shows the second-best combination of explicit and implicit weights on the objective performance measure (in bold). See text for definition of variables.

Figure 42

\section{Implications, Discussion and Evidence}

We next explore the implications of the models developed in Sections 3 and 4, and show how certain aspects of compensation systems used in organizations can be understood as optimal contracts consistent with our results. We discuss three particular implications of our model: that effective explicit incentive contracts may increase the use of implicit contracts, that a decline in the profitability of a firm will reduce the use of implicit contracts and increase the use of explicit ones, and that a reduction in the accuracy of subjective performance measures will also reduce the use of implicit and increase the use of explicit contracts. We also highlight examples where the weights attached to objective performance measures are subjective rather than objective.

\section{The Effect of Objective Performance Measures on the Use of Implicit Contracts}

The results presented in Section 3 suggest that, rather than acting strictly as substitutes in the provision of incentives, objective and subjective performance assessment systems may reinforce one another. We present two such situations, and discuss how our model helps explain each. 
As discussed in the Introduction, Lincoln Electric Company uses large amounts of both objective and subjective performance assessment in its incentive plan.11 Workers are well-paid and productive: compensation at Lincoln Electric is about twice the average for manufacturing employees, and productivity is more than twice the industry average. There is no base salary. Workers receive about half their pay from a piece rate based strictly on the quantity of items produced.12 The rest of a worker's compensation comes in the form of a year-end bonus, which is distributed to employees based on a purely subjective merit rating made by the employee's supervisor. The subjective ratings are based on such factors as dependability, quality, output, and "ideas and cooperation."13

That Lincoln Electric uses such a large amount of subjectively determined bonus in combination with the objectively determined piece rate is consistent with our models. Indeed, our model in Section 3 suggests that the objective incentive contract helps the firm sustain such a rich subjective bonus plan. The year-end bonus payments represent half of the pre-tax, pre-bonus profits of the company, or approximately twice net income after taxes. The firm has a strong incentive to renege on its promise to pay these bonuses, but the fact that the workers are so productive (due in part to the success of the piece-rate system) makes the ongoing relationship very valuable and so makes the implicit contract self-enforcing. Workers understand this, and agree to a contract with a large subjective bonus component. The president of Lincoln Electric, George Willis, also understands the importance of implicit contracts and trust at the company: he said in 1975 that "If our employees did not believe that management was trustworthy, honest, and impartial, the system would not operate."

Lincoln Electric's bonus plan also illustrates the use of subjective weights on objective performance measures. Notice that the quantity of output is a criterion for the subjective bonus. This objectively measured factor, although rewarded by the explicit piecerate contract, is given additional weight through the subjective bonus plan. Our model in Section 4 provides a rationale for such a combination of contracts: the subjective weights allow the firm to "back out" unintended dysfunctional behavior induced by the piece-rate incentives. The firm can use its subjective observations of the conditions actually faced by the workers to adjust the total incentives provided for quantity.

11 The material in this subsection comes from Berg (1975), Baldwin (1982), and Perry (1988).

12 In addition, workers stencil their names on everything that they produce. Quality problems, whether discovered by inspectors $\alpha$ customers, are corrected by the workers on their own time.

13 Interestingly, Lincoln relies on another kind of implicit contract in administering its piece-rate contracts. To avoid the ratchet effect that can plague piece-rate systems (Roy, 1952; Gibbons, 1987), the firm's stated policy is that changes in the piece price will occur only after important technological innovations. As with an implicit incentive contract, this rate-changing policy is vulnerable to reneging by the firm. Lincoln again solves this problem by staking its reputation. 
A second organizational context, the leveraged buyout of $0 . M$. Scott, also illustrates the interaction of subjective and objective bonus plans. $14 \mathrm{O}$. M. Scott had been a division of ITT, a multi-national conglomerate. Under ITT, the company had a modest bonus program that provided small payments with almost no time-series variation in rewards. Following the LBO, the new majority-owner (investment banker Clayton \& Dubilier) introduced a redesigned compensation system that substantially increased the variation in time-series payoffs and changed the way performance was measured.

As at Lincoln Electric, the post-LBO O. M. Scott uses a combination of subjective and objective measures of performance. Bonuses for the top managers of the firm are determined by a formula that places a $50 \%$ weight on the attainment of corporate goals, and $50 \%$ weight on the attainment of individual-specific personal goals. ${ }^{15}$ Corporate performance goals are based on quantitative cash-flow-based measures such as earnings before interest and taxes (EBIT) and average working capital (AWC). The personal goalsnegotiated annually between the manager and his or her superior-include accomplishment of specific tasks and performing particular activities. The attainment of personal goals is assessed by the manager's superior.

The increased reliance on subjective performance measures in the O. M. Scott bonus plan following the LBO is consistent with the intuition provided in Section 3. The financing of the LBO imposed new financial obligations on the company to pay out substantial cash flow over a ten-year period. These obligations gave the firm a new and better-defined set of corporate goals- to generate cash from operations and to make efficient use of its working capital-that lend themselves well to explicit incentive contracts based on EBIT and AWC. Such a change could be modeled as decreasing $\operatorname{var}(\mu)$, the distortion in the objective performance measure. According to the comparative-static results in Section 3, such a change can increase the use of subjective measures because the increased profits resulting from superior objective performance measurement permit stronger incentives through implicit contracts. At O. M. Scott, as the relative efficiency of the cash-flow-based objective measures increased the value of the relationship between the company and the managers, Clayton \& Dubilier was able to increase the use of a subjective performance evaluation system.

14 This data is drawn from Baker and Wruck (1989).

15 Division management received bonuses based $40 \%$ on divisional financial performance, $35 \%$ on corporate performance, and $25 \%$ on attainment of individual goals. 
The Decline of Trust at IBM

Recent events at IBM also are consistent with the models presented in Section 3 . In particular, the company's aggressive early retirement programs, its abandonment of its lifetime employment policy, and its reorganization (and even spinning off) of its business units can all be seen as responses to the firm's and the employees' recognition that the firm will not be as profitable in the future. ${ }^{16}$ This decline in the value of future cooperative relationships between firm and worker leads to increased difficulty in maintaining implicit incentive contracts.

IBM's recent "voluntary" early retirement programs began in response to several years of declining profitability, as well as recognition by top management that the future prospects for its mainframe computer business were not good. Press accounts describe several aspects of the program that suggest that early retirements were not necessarily voluntary. Supervisors were encouraged to suggest the program to certain managers, and managers who received such suggestions speculated that if they did not accept the offer quickly, a less generous future severance offer could be the result. The firm was also reported to be using several techniques to cut employment while avoiding formal lay-offs, including moving unproductive employees from staff to line positions, where their poor performance could be documented and they could be terminated "for cause."

The fact that IBM tried so hard to appear to honor its lifetime-employment implicit contract, but that this attempt was met with such skepticism by employees, indicate both top management's perception of the value of this contract and employees' (and ultimately top management's) recognition that the company would no longer honor it. One response to this loss of trust in the implicit contracts at IBM has been a wholesale reorganization of the firm's business units, including a major change in how the company measures performance. According to an article in the internal IBM magazine, the company has begun to report "performance data-revenue, profit, cash, returns, etc.-[that] will constitute the set of criteria against which each business will be measured" (Iwata, 1992). According to Lohr (1992), "Everyone is a . . p profit center, selling to each other and to outsiders. That mentality is nurtured by constantly measuring performance and customer satisfaction, and rewarding the teams who do the best." These newly independent units rely much less on the implicit contracts backed by the reputation of IBM as a whole, and instead use explicit incentive contracts and objectively determined bonuses. The models presented in Section 3 predict just such a response to the declining future profitability of the firm.

16 The information in this subsection is drawn from McGec (1991), Schrage (1986), Lohr (1992), Iwata (1992), and Hooper (1993). 


\section{Subjective performance assessment at Bennett, Strang and Farris}

Our model predicts that as subjective performance measures become less accurate, firms will tend to decrease reliance on implicit-contract bonus plans, and will instead use more objectively determined bonuses. Such a decline in the accuracy of subjective measures seems inevitable as furms grow and increase in complexity. David Maister, an expert on professional partnerships, describes typical problems related to partner performance evaluation and compensation in a composite law firm he called Bennett, Strang, and Farris (BSF). 17

Maister's case describes the evolution of BSF. When the firm was small, the actively involved founders could closely monitor partner performance and make careful and informed subjective evaluations of each partner's contribution to the value of the firm. Annual profits were divided among partners solely at the discretion of the firm's three founders and named partners. There was no need for a formal appeals process for compensation-related complaints since the top partners were generally able to convince unhappy individuals that they had taken reasoned judgments.

Over the following decades, the firm grew in profitability and size by expanding into a full-service law firm, offering legal services in a wide range of practice areas. Compensation decisions, once made by the long-since-retired founding partners, rested with a democratically elected seven-member compensation committee. Increasing dissatisfaction with the subjective nature of the evaluation process led the firm to adopt formal guidelines to assess performance, based on objective data such as partner age and seniority, billable hours, fees collected, time spent on other partners' clients, origination credits, bill collection rates, and so on. Without explicitly placing weights on these measures, the committee used these data to allocate the partnership profit pool. Consistent with our analysis of subjective weights on objective performance measures (in Section 4), the committee was concemed that specifying explicit weights would lead the partners to focus on the bonus formula rather than firm profitability.

By the end of Maister's case, the compensation system at his composite law firm was coming under increasing fire from partners for not being "objective” enough. Partners were concerned that they compensation committee lacked sufficient information to make appropriate subjective assessments. The announcement of the compensation committee's

17 Formerly a professor at Harvard Business School, Maister founded and now heads a firm that consults to professional partnerships. We refer to his case, "Bennett, Strang and Farris." 
recommendations prompted a disputatious partners' meeting, and a call for a thorough review of the compensation system.

Analysis of this case in light of the model presented in Section 3 suggests that a major factor contributing to the changes and controversy surrounding compensation at BSF was the growth in firm size and complexity. This increased the difficulty for any one person (or small group) to assess the incremental contribution of a partner to the value of the entire firm. Subjective evaluations by the compensation committee were thus more likely to be viewed as inaccurate, and so more likely to lead to distorted incentives for the partners. If we model growth in size and complexity as increases in the variance of the distortion in the subjective performance measure, $\operatorname{var}(\varepsilon)$, the law firm's move towards heavier reliance on objective measures is consistent with our comparative-static prediction in Section 3B.

\section{Summary and Extensions}

This paper is a first step in the analysis of subjective performance assessment. The paper brings formal analysis to questions about incentive contracts that have been only informally treated in the past. Specifically, we model trust in subjective compensation contracts, using the requirement that such contracts be self-enforcing. We feel that, like Kreps' (1990) game-theoretic analysis of corporate culture, the paper shows promise for the use of formal techniques in the analysis of topics previously considered "too soft" for such work. The effectiveness of incentive contracting in organizations depends on a large set of social, psychological, and economic factors, only a few of which have been explored by economists. We hope we have expanded this set a little.

There are many aspects of the problem we have not yet addressed. In Section 3B, for example, we suggested that the worker's private information $\varepsilon$ that affects the imperfect subjective performance assessment $q$ may be a first step towards modeling supervisor bias. It would be natural to extend the model to explore the use of multiple evaluators in subjective performance assessment systems. Suppose that the $i^{\text {th }}$ supervisor's subjective cvaluation involves a distortion $\varepsilon_{i}$, and that workers "game" the performance-appraisal process by taking actions that are perceived favorably by a particular supervisor. If the distortions are independently distributed across supervisors, the gaming can be mitigated by combining the subjective performance evaluations of several supervisors. ${ }^{18}$

As an example, most promotion and tenure decisions at universities are made by committees of senior faculty members. Although objective performance measures such as

18 Prendergast and Topel (1992) make a similar suggestion. 
number of publications or teaching-evaluation ratings are used in the process, the ultimate decision is generally based on a highly subjective evaluation of the candidate's expected contribution to the value of the university. Individually, each committee member may have idiosyncratic biases or predispositions such as emphasizing teaching over research, or research over teaching, or collegiality, or viewing specific types of research as particularly favorable. A candidate evaluated by a single senior faculty member could focus on activities viewed favorably by that particular senior colleague, independent of the effect of these activities on the value of the organization. Basing decisions on the evaluations of several senior colleagues, each with their own set of biases and predispositions, is much harder to game in a similar fashion. 19

The supervisorial biases discussed so far reflect ways in which supervisors misinterpret performance data, but do not reflect explicit favoritism on the part of the evaluator. One way to begin to model such favoritism would be to allow the supervisor to observe q privately (rather than publicly with the worker, as in Section 3B), and then to analyze the supervisor's incentive to report $q$ truthfully. This potential exercise of managerial discretion over truthfully reporting the performance measure suggests another role for trust in the performance-evaluation process: workers don't trust subjective performance evaluation when they feel that supervisors indulge in favoritism.

Finally, although it departs from our focus on pay for performance, a further extension of our approach merits attention. Perhaps the most pervasive performance-based implicit contract in most organizations pertains to promotions. Just as we have analyzed the interplay between implicit and explicit pay-for-performance contracts, one could also combine implicit promotion contracts with explicit pay-for-performance contracts.

In the present paper, a one-shot implicit contract creates no incentives (because the firm will renege on any promised bonus payment), but implicit contracts in ongoing relationships can create incentives (as analyzed in Section $2 \mathrm{C}$ ). When these repeated-game incentives are inefficiently low (perhaps because the discount rate or alternative wage is too high), there is scope for imperfect explicit contracts, both to provide additional incentives and (more interestingly) to increase the value of the relationship, thereby allowing stronger implicit-contract incentives.

In an analogous paper on promotions, even a one-shot implicit contract could create some incentives. Waldman (1984), Kahn and Huberman (1988), and Prendergast (1993), for example, consider two-period models in which the firm's promotion decision is made on

19 In addition, keeping the identities of the evaluators confidential during the promotion and tenure process-effectively hiding information abou $\varepsilon$ from the promotion candidate-is another way to mitigate gaming. 
a subjective basis-that is the promotion contract is implicit-but the firm chooses to promote some workers anyway because of the resulting second-period profit: workers with sufficiently valuable ability or training are worth promoting to a higher-paying job. In these models, the firm's job assignments and the worker's investment in training are generally not first-best. In repeated-game versions of these promotion models (in which the firm lives forever and workers arrive in overlapping two-period generations), the firm's decision to promote a worker would be based on profits from both the current and future workers, so job assignments and investment decisions would typically be more efficient than in the oneshot case. As in the present paper, however, these job assignments and investment decisions could still be somewhat inefficient, again creating scope for imperfect explicit pay-forperformance contracts. 


\section{Appendix}

\section{Comparative Statics for Case 2: $V\left(\beta^{*}\right)<0$}

This Appendix solves for the optimal $b^{* *}$ and $\beta^{* *}$ for the case when the explicit contract in the absence of implicit performance measures is unprofitable, $V\left(\beta^{*}\right)<0$, and derives the comparative statics results reported in equation (3.7). When $V\left(\beta^{*}\right)<0$, the reneging constraint is not $V(b, \beta)-V\left(\beta^{*}\right) \geq r b$ as in (3.1) but rather $V(b, \beta) \geq r b$, where (using (2.2), (2.5), and (2.9))

$$
\begin{aligned}
V(b, \beta) & \left.\equiv E_{\mu 2}\left(a^{*}(\mu, b, \beta)-a^{*}(\mu, b, \beta)^{2}-w_{a}\right)\right), \\
& =\frac{1}{4 \gamma}\left(2(b+\beta-b \beta)-b^{2}-\beta^{2}(1+\operatorname{var}[\mu])\right)-w_{a}
\end{aligned}
$$

The optimal contract sets $b$ and $\beta$ to maximize expected profit $V(b, \beta)$, subject to the reneging constraint $V(b, \beta) \geq r b$. Defining $\lambda$ as the Lagrange multiplier for this constraint, the firstorder conditions for the optimal contract involving both subjective assessments and objective measures (i.e., when $b>0$ and $\beta>0$ ) are:

(A.2a) $\quad(1+\lambda) \cdot(1-b-\beta)=2 \lambda \gamma \tau$,

(A.2b) $\quad(1+\lambda) \cdot(1-b-\beta \cdot(1+\operatorname{var}[\mu]))=0$,

The first-order conditions (A.2a) and (A.2b) are identical to (3.2a) and (3.2b) for the case $V\left(\beta^{*}\right)>0$. Equation (A.2b) yields $\beta^{* *}(b)$, the optimal $\beta$ given an arbitrary value of $b$.

$$
\beta^{* *}(b)=(1-b) \cdot \frac{1}{1+\operatorname{var}(1)} \text {. }
$$

For parameter values such that the first-best implicit contract $b^{* *}=1$ is not feasible, the optimal implicit-contract bonus $b^{* *}$ is the largest value of $b$ solving

$$
V\left[b, \beta^{* *}(b)\right]=\frac{1}{4 \gamma}\left(-b^{2} k+2 b k+1-k\right)-w_{a}=r b,
$$

where $k=\operatorname{var}(\mu) /[1+\operatorname{var}(\mu)]<1$. Equation (A.4) is a quadratic of the form $A b^{2}+B b+C$ $=0$, where $A=-k, B=2 k-4 \gamma r$, and $\left.C=1-k-4 \gamma w_{a}\right)$. If $B^{2}+4 k C>0$ then there exists an interval of values of $b$ satisfying the constraint. The solution is the largest value of $b$ in $[0,1]$ that satisfies the constraint:

$$
b^{* *}=\frac{B+\sqrt{B^{2}+4 k C}}{2 k} .
$$


Since $b^{* *}$ decreases with $k$, the largest value of $b$ satisfying (Al.3) exceeds that satisfying (A1.4): $b^{* *}>b^{*}$. Since $C$ decreases with $w_{a}$, the fact that $\partial b^{* *} \partial C<0$ implies that $b^{* *}$ decreases with $w_{a}$. Similarly, $b^{* *}$ increases with $B$ and thus decreases with $r$. Also, as $\operatorname{var}(\mu)$ increases, $k$ increases (approaching unity), so $b^{* *}$ decreases. To summarize,

$$
\frac{\partial b^{* *}}{\partial \mathrm{r}}<0, \quad \frac{\partial b^{* *}}{\partial w_{a}}<0, \quad \frac{\partial b^{* *}}{\partial \operatorname{var}(\mu)}<0,
$$

The comparative-statics for the explicit-contract bonus $\beta^{* *}$ follow from (A.3),

$$
\frac{\partial \beta^{* *}}{\partial r}>0, \quad \frac{\partial \beta^{* *}}{\partial w_{a}}>0, \quad \frac{\partial \beta^{* *}}{\partial \operatorname{var}(\mu)} \gtrless 0 .
$$




\section{References}

Abreu, Dilip. 1988. "On the Theory of Infinitely Repeated Games with Discounting." Econometrica 56:383-96.

Baker, George. 1992. "Incentive Contracts and Performance Measurement." Journal of Political Economy 100:598-614.

and Karen H. Wruck. 1989. "Organizational Changes and Value Creation in Leveraged Buyouts: The Case of the O.M. Scott \& Sons Company." Journal of Financial Economics 25:163-90.

Baldwin, William. 1982 "This is the Answer." (July 5).

Becker, Gary and George Stigler. 1974. "Law Enforcement, Malfeasance, and Compensation of Enforcers." Journal of Legal Studies 3:1-18.

Berg, Norman. 1975. "The Lincoln Electric Company." HBS Case \#376-028.

Bull, Clive. 1987. "The Existence of Self-Enforcing Implicit Contracts," Quarterly, Journal of Economics 102:147-59.

Eccles, Robert G. and Dwight B. Crane. 1988. Doing Deals: Investment Banks at Work. Harvard Business School Press.

Fudenberg, Drew, and Jean Tirole. 1991. Game Theory. MIT Press.

Gibbons, Robert. 1987. "Piece-Rate Incentive Schemes." Journal of Labor Economics 5:413-29.

Hamner, W. Clay, "How to Ruin Motivation with Pay," Compensation Review, Vol. 7, No. 3 (3rd Quarter, 1975), pp. 17-27.

Holmström, Bengt. 1979. "Moral Hazard and Observability." Bell Journal of Economics 10:7-91.

1981. "Contractual Models of the Labor Market." American Economic Review 71:308-13.

and Paul Milgrom. 1991. "Multitask Principal-Agent Analyses: Incentive Contracts, Asset Ownership, and Job Design." Journal of Law, Economics, and Organization, 7:24-52.

Hooper, Laurence. 1993. "IBM Grants Gerstner Pay Package Valued At Up to $\$ 3.5$ Million," Wall Street Journal (March 31)

Iwata, Jon. 1992. "Redefining the IBMer: From Employee to Entrepreneur." Think, No. 2. (IBM Internal Magazine.)

Kahn, Charles and Gur Huberman. 1988. "Two-sided Uncertainty and 'Up-or-Out' Contracts." Journal of Labor Economics. 6:423-44.

Klein, Benjamin and Keith Leffler. 1981. "The Role of Market Forces in Assuring Contractual Performance." Journal of Political Economy 81:625-41.

Kreps, David. 1990. "Corporate Culture and Economic Theory." In J. Alt and K. Shepsle, eds. Perspectives on Positive Political Economy. Cambridge University Press. 
Lawler, Edward E. II. 1971. Pay and Organizational Effectiveness: A Psychological View, New York: McGraw-Hill.

Lohr, Steve. 1992. "Pulling One's Weight at the New I.B.M." New York Times (July 5).

MacLeod, Bentley, and James Malcomson. 1989. "Implicit Contracts, Incentive Compatibility, and Involuntary Unemployment." Econometrica 57:447-80. and 1993. "Wage Premiums and Profit Maximization in Efficiency Wage Models." European Economic Review, forthcoming.

Maister, David. 1983. "Bennett, Strang, and Farris." HBS Case \#9-684-027.

McGee, Marianne Kolbasuk. 1991. “Can IBM Retain its Full Employment Policy?" Management Review (September 1).

Merchant, Kenneth. 1989. Rewarding Results: Motivating Profit Center Managers. Harvard Business School Press.

Patterson, Gregory. 1992. "Distressed Shoppers, Disaffected Workers Prompt Stores to Alter Sales Commission," Wall Street Journal (June 1).

Perry, Nancy. 1988. "Here Come Richer, Riskier Pay Plans," Fortune (December 19).

Post, Richard J. and Kenneth E. Goodpaster. 1981. "H.J. Heinz Company: The Administration of Policy," HBS Case \#382-034.

Prendergast, Canice. 1993. "The Role of Promotion in Inducing Specific Human Capital Acquisition." Quarterly Journal of Economics, forthcoming.

and Robert Topel. 1992. "Subjective Performance Evaluation." Mimeo, University of Chicago.

Roberts, Johnnie L. 1989. "Credit Squeeze: Dun \& Bradstreet Faces Flap Over How It Sells Reports on Businesses," Wall Street Journal (March 2).

Roy, Donald. 1952. "Quota Restriction and Goldbricking in a Machine Shop," American Journal of Sociology 57:427-42.

Schrage, Michael 1986. "IBM Rethinking Cherished Policy of No Layoffs." The Washington Post (June 27).

Shapiro, Carl. and Joseph Stiglitz. 1984. "Equilibrium Unemployment as a Discipline Device." American Economic Review 74:433-44.

Waldman, Michael. 1984. "Job Assignments, Signalling, and Efficiency." Rand Journal of Economics 15:255-67. 